\title{
On the pro-trade effects of immigrants
}

\author{
Massimiliano Bratti • Luca De Benedictis • Gianluca Santoni
}

(C) Kiel Institute 2014

\begin{abstract}
This paper investigates the causal effect of immigration on trade flows using Italian panel data at the province level. We exploit the exceptional characteristics of the Italian data (the fine geographical disaggregation, the very high number of countries of origin of immigrants, the high heterogeneity of social and economic characteristics of Italian provinces, and the absence of cultural or historical ties with the countries where immigrants come from) coupled with the use of a wide set of fixed effects and an 'instrument' based on immigrants' enclaves. We find that immigrants have a significant positive effect on both exports and imports, but much larger for the latter. The pro-trade effects of immigrants tend to decline in space, and even turn negative when large ethnic communities are located too far away from a specific province (via a trade-diversion effect). Moreover, while our data show inter-ethnic spillovers for exports, we find no evidence that networks between different ethnicities affect provinces' imports. Finally, we provide evidence of a substantial heterogeneity in the effects of immigrants: the impact on trade tends to be larger for immigrants coming from low-income countries, for earlier waves of immigrants, and for least advanced provinces (Southern Italy).
\end{abstract}

Electronic supplementary material The online version of this article (doi:10.1007/s10290-014-0191-8) contains supplementary material, which is available to authorized users.

M. Bratti

DEMM, Università degli Studi di Milano, Via Conservatorio 7, 20122 Milan, MI, Italy

e-mail: massimiliano.bratti@unimi.it

L. De Benedictis $(\bowtie)$

DED, Università degli Studi di Macerata, Via Crescimbeni 20, 62100 Macerata, MC, Italy e-mail: luca.debenedictis@unimc.it

G. Santoni

IE, Scuola Superiore Sant'Anna, Piazza Martiri della Liberta, 33, 56127 Pisa, PI, Italy

e-mail: g.santoni@sssup.it 
Keywords Immigration - Trade - Gravity model · Transplanted home

bias effect $\cdot$ Business and social networks effects

JEL Classification $\mathrm{F} 10 \cdot \mathrm{F} 14 \cdot \mathrm{F} 22 \cdot \mathrm{R} 10$

\section{Introduction}

At the turn of the twenty-first century, about $3 \%$ of world population is living in a different country from the one of origin. Similarly, more than $20 \%$ of world production is sent to a different country from the one where it is originated. In dynamic terms, both migration and trade are growing at a very similar rate (Docquier and Rapoport 2012). This paper is about the link between these two flows, the movement of people and the movement of goods.

The positive correlation between migration and trade has been widely documented (WTO 2013) and, in the last 20 years, many contributions, starting from the one of Gould (1994), sharpened our knowledge about the interlinkages between these two phenomena. However, the clear identification of the direct causal effect of immigrants on trade flows involving the country of origin and the area of settlement is not as smooth as it might appear. Estimates can be spoiled by the reverse causality inherent to the fact that immigrants generally move to countries where formal or informal links were already established and where trade with their homeland was already preexistent. Common determinants, some of them unobservable, can contemporaneously affect both migration and trade. Specific characteristics at the country of origin level, at the trading-pair level, and at the local level in the host country, if not considered in the analysis can significantly bias the coefficient of interest: the immigration elasticity of trade flows.

The paper-that focuses on the case of Italy between 2002 and 2009-is organized as follows. Section 2 acts as a cornerstone and discusses the literature on the pro-trade effects of immigrants, highlighting the traditional mechanisms behind the commonly observed positive effect, the main empirical obstacles to the identification strategy, and the solutions proposed by previous contributions. Section 3 describes the characteristics of the Italian case and discusses the anthropological notion of 'super-diversity' in immigration and its applicability to contemporary Italy; points out the great economic and geographical heterogeneity of the country; and presenting and summarizing the data used in the analysis underlines the main advantage of working with two different levels of spatial units, the regional and the provincial level, in order to directly tackle the issue of the Modifiable Areal Unit Problem (MAUP) and its implications for the empirical analysis. Section 4 includes the benchmark empirical results and stresses the original contributions of the present paper with respect to the existing literature. First, the risk of a spurious correlation between trade and immigration is minimized owing to the very fine geographical scale of the analysis at the provincial level. This also allows us to analyze the implications of the MAUP for the trade-immigration link, to investigate geographical spillovers of immigrants on trade (Sect. 5) and to 
identify spillover causal effects. Second, the extensive country coverage of our dataset ensures that any sample selection bias stemming from the specific choice of the foreign countries entering the analysis has been minimized. Third, unlike most functional forms estimated in the literature we allow for inter-ethnic spillovers. Our specification (Sect. 5.2) allows for immigrants of other nationalities to affect trade between an Italian province and a specific foreign country. Fourth, to rule out the possibility of an endogeneity bias that could inflate our coefficients of interest, we control for omitted common determinants including time-varying foreign-countryspecific, time-varying region-specific and trading-pair fixed effects in the regressions. In Sect. 6, we also make use of an Instrumental Variables (IVs, hereafter) approach à la Altonji and Card (1991), where the geographical distribution of immigrants' residence permits in 1995 (the earliest year for which comparable geographical data are available) and immigrants' flows at the nationwide level serve to compute an instrument (the imputed stock of immigrants). Fifth, we bring to the data the two main explanations highlighted in the literature: the business and social network effect à la Rauch (2001) (i.e., immigrants foster both bilateral imports and exports because of their superior knowledge of, or preferential access to, market opportunities in their home country) and the transplanted home bias effect (Gould 1994; White 2007) (i.e., immigrants promote imports of their home country consumption-goods to satisfy their different consumption tastes) estimating the pro-trade effect of immigrants on both export and import flows. Finally, we give evidence (Sect. 7) of the heterogeneous effects of immigrants on trade according to the level of per capita income of their country of origin, their education level, the timing of arrival (distinguishing between ethnic groups participating to the first or the second wave of immigration) and their geographical location in Italy (distinguishing between Northern and Southern Italy).

Section 8 summarizes the paper's main findings. The Online-Appendices include the full description of the variables used, the list of the foreign countries considered in the analysis, a discussion of the role of fixed effects in saturating the empirical model, a description of the empirical attempts related to the inclusion of zero-trade flows in the analysis, and the discussion of the peculiar role played by large Italian cities such as Rome and Milan.

\section{A selective literature review}

The international trade literature based on the estimate of a gravity equation-where trade flows between a regional entity $i$ and its international counterpart $j$ are positively associated with economic attractors, such as the GDPs of $i$ and $j$, and negatively associated with obstacles to international trade, such as geographical distance—has generally found a strong association between immigration and trade. ${ }^{1}$ The presence in $i$ of immigrants from $j$ can be considered as force of attraction,

\footnotetext{
${ }^{1}$ See De Benedictis and Taglioni (2011) for an empirically oriented review of the literature on the gravity model in international trade, and Head and Mayer (2014) for a state of the art survey.
} 
fostering international trade between $i$ and $j$. Different studies (Head and Ries 1998; Dunlevy and Hutchinson 1999; Rauch and Trindade 2002; Girma and Yu 2002; Coughlin and Wall 2011), using different samples, periods and estimation techniques have generally reported a strong positive association between immigrants and trade. Some recent papers have also made attempts to qualify such association as causal using IVs methods (Briant et al. 2009; Peri and RequenaSilvente 2010).

In Fig. 1 we summarize the results of a sample of relevant contributions to the literature in terms of the estimated elasticity of trade to the stock of immigrants. Black dots depict imports, white dots exports, and black horizontal segments indicate $95 \%$ confidence intervals. The two vertical dotted lines correspond to the meta-modal elasticity estimated in Genc et al. (2012), which is 0.12 for exports and 0.15 for imports. As it is evident, the estimates show a high degree of variability. Between the seminal contribution by Gould (1994), that basically gave origin to this new stream of research, and 2002, the literature was dominated by cross-country studies. Wagner et al. (2002) established the standard in the subsequent set of contributions, highlighting the role of two fundamental ingredients: (a) country-fixed effects, to control for omitted variable bias; (b) the use of regional data, to exploit cross-sectional variation on trade and immigration at the sub-national level (for Canada, in their original analysis) and to deal with the endogeneity bias mentioned in Sect. 1. Since Wagner et al. (2002) the variability in the estimates reduces substantially.

Figure 1 shows one first important evidence of the literature: the elasticity of imports to immigrants is higher than that of exports, and both are positive and generally significantly different from zero. This is generally rationalized calling upon two common explanations of the pro-trade effects of immigrants. The main explanation is rooted in the idea that information costs play a major role in the fixed cost that firms pay to enter foreign markets. In the seminal contributions of Rauch (1999, 2001), ethnic networks related to migration flows are likely to reduce some of these information costs. Cross-border networks of people sharing the same country of origin can substitute or integrate organized markets in matching international demand and supply. ${ }^{2}$

A further point associated with this first explanation is related to the characteristics of immigrants and how these characteristics can reduce the fixed cost of exporting. Language, specific knowledge of homeland institutions and norms, familiarity with homeland (excess) demand, can bridge the home country and the host country, if these assets are positively valued and acquired by firms producing in the country were immigrants settled (Wagner et al. 2002; Peri and Requena-Silvente 2010). Moreover, "immigrant networks may provide contract enforcement through sanctions and exclusions, which substitutes for weak institutional rules and reduces trade costs," (Briant et al. 2009). Following Rauch (2001), this explanation has been named the business and social network effect of immigrants on trade.

\footnotetext{
2 Several studies have explored the role of ethnic networks in international trade since Rauch (2001). See, among others, Rauch and Trindade (2002), Epstein and Gang (2004), Felbermayr et al. (2010), Coughlin and Wall (2011), and Hiller (2013).
} 


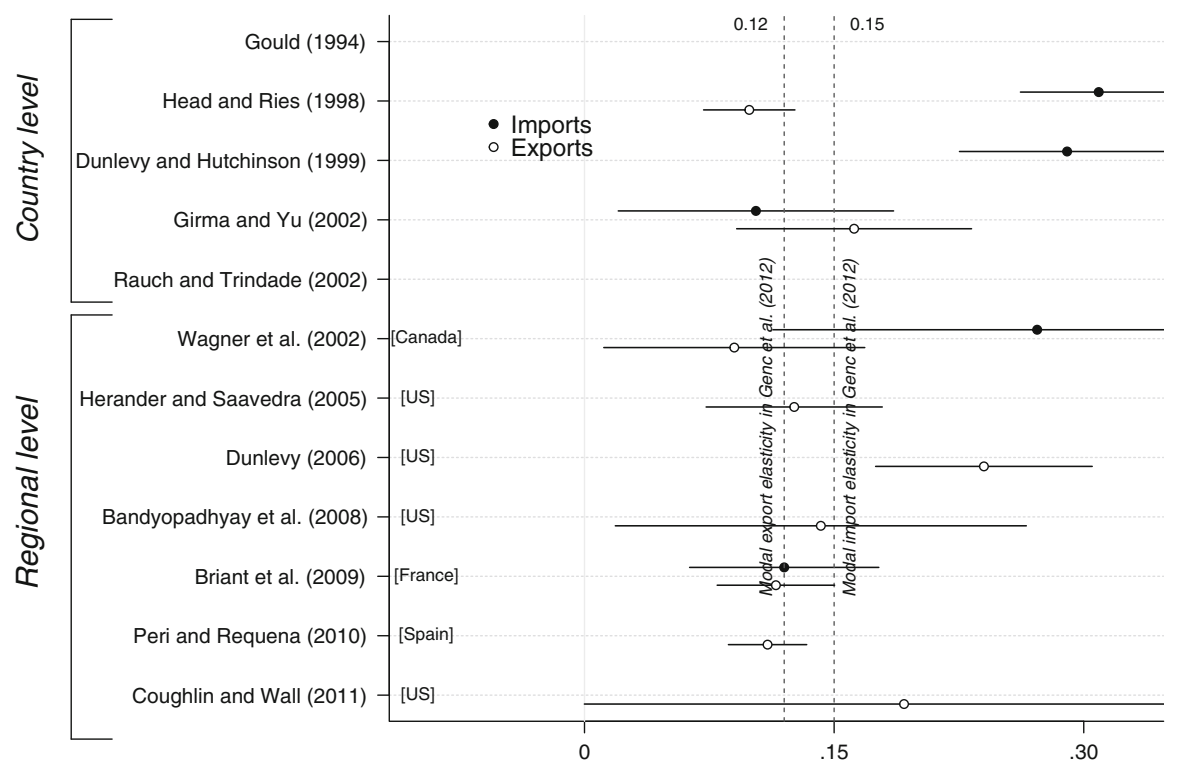

Fig. 1 The figure plots estimates obtained from several contributions to the literature on the effect of immigration on trade. Black dots indicate the elasticity of imports to immigrants, white dots that of exports, black horizontal segments indicate $95 \%$ confidence intervals. The two dotted vertical lines correspond to the meta-modal elasticity estimated in Genc et al. (2012), which is 0.12 for exports and 0.15 for imports. The horizontal axis is trimmed for visual purposes. The seminal contribution by Gould (1994) did not use a gravity equation framework and the estimated elasticities are not comparable and omitted from the plot. The complete list of papers is included in the References

The second, less explored explanation, is that immigrants are characterized by different habits in consumption with respect to natives, and they may slowly modify their original home-biased demand after settling in the host country (see Gould (1994) for an innovative discussion of the issue). Since homeland goods are more costly in the host country, immigrants have an incentive to buy those goods from the home country itself. Proper empirical evidence on what has been called by White (2007) the transplanted home bias effect of immigrants on trade was, until recently, basically non existent (White and Tedesse 2007). The significance and magnitude of the effect was generally inferred from the difference between the estimated immigrant-elasticity of imports (to which both effects were contributing) and exports (not affected by the transplanted home bias effect). Since, as it is evident from Fig. 1, the immigrants elasticity of imports tends to be higher than that of exports, this was interpreted by deductive reasoning as supporting the idea that there should be something forcing the two elasticities to be different, and this 'something' was attributed to a persistent difference in tastes between immigrants and natives. Yet it must be noted that the presence of immigrants might also result in the medium or long term in a certain shift of province's $i$ production toward the preferences of immigrants. This shift raises chances of exporting to country $j$, while it also reduces the need for immigrants and natives to satisfy their specific demands from country $j$, 
thus possibility decreasing imports between $i$ and $j$. Hence, there is no particular reason to believe that, in the long run, the trade-enhancing effect of immigrants would be larger for imports than for exports.

Recently, some more clear evidence of the relevance of the transplanted home bias effect has been provided by Bronnenberg et al. (2012), Mazzolari and Neumark (2012) and Atkin (2013) using microdata.

While more recent contributions have disregarded the effect of immigrants on imports (see the regional-level estimates in Fig. 1), in the following analysis we look at both the export and import elasticities to immigrants, so as to give quantitative content to both the business and social network effect and the transplanted home bias effect of immigrants on trade.

\section{Italy as a case study: motivation, data and descriptive statistics}

Following Wagner et al. (2002) and the subsequent contributions discussed in the previous section, our analysis takes a single-country perspective examining the Italian case during the 2000s. Looking at this specific case has not only an interest per se, but offers many insights on a more general basis. First, Italy shares some common features with many (OECD and non-OECD) immigration countries: in the year 2000, the percentage of the Italian population that was born abroad was $4.1 \%$, and it grew steadily between 2000 and 2009, reaching the total number of 4.2 million foreign-born residents, meaning that $7 \%$ of Italian residents were born in a different country (ISTAT 2011). Second, the large heterogeneity of the countries of origin of immigrants in Italy makes the Italian case relevant for other recipient countries as well. Moreover, the very fine geographical disaggregation of the Italian longitudinal data on trade and migration allows us to adopt a reliable empirical strategy for the identification of the effect of immigration on international trade. For all these features, we think that our analysis offers some generally informative indications on the interplay between immigration and international trade, giving a contribution to the ongoing policy debate on the issue.

The Italian immigration case is characterized by what anthropologists call "super-diversity" (Vertovec 2007), a notion intended to emphasize the level and kind of complexity in immigrants' social and economic participation in national everyday life, way above anything the country had previously experienced. The relevant ingredients of super-diverse immigration are “...the increased number of new, small and scattered, multiple-origin, transnationally connected, socio-economically differentiated and legally stratified immigrants who have arrived over the last decade," (Vertovec 2006). This seems to fit Italy quite well.

In Italy, the phenomenon of massive immigration is quite recent. Italy was a land of emigrants at least until the 1960s, and the migration balance started showing a positive sign only in the 1970s. To the traditional ethnic groups coming from North Africa, often on a temporary basis, a new diaspora of permanent (essentially housemaid) workers entered Italy from the Philippines, Cape Verde and Sri Lanka. In the 1980s, immigrants coming from Central Africa (Senegal, Nigeria, Côte d'Ivoire, Burkina Faso), South America (Peru, Dominican Republic), the Indian 
sub-continent (India, Pakistan and Sri Lanka again) and Asia (China) settled permanently in Italy. The more recent wave of immigration took place in the 1990s. It started in 1991 with the dramatic outflow from Albania and became even more numerically relevant with the fall of the Berlin Wall and the entrance of Poland, first, and Romania, afterwards, in the European Union. The 2000s-covered by our analysis - is a period of growing immigration characterized by the emergence of new ethnic groups and the downsizing of others. As a result, the geographical coverage of the Italian immigration data is remarkable, allowing to account for 187 countries of origin of immigrants. ${ }^{3}$

In our empirical analysis, we turn to our advantage the minimal historical participation of Italy to colonialism. As emphasized by Briant et al. (2009), in country-level analyses there are very good reasons to suspect that the correlation between trade and immigration might depend on one or more omitted common determinants (such as colonial ties, common language or cultural proximity). In the Italian case, differently from other cases such as the UK (and the London area in particular) or France and the US (and the New York area in particular), the superdiversity of the many ethnicities now living in Italy is largely unrelated to colonial heritage, linguistic or genetic proximity or institutional and cultural similarity. This characteristic of the Italian case is therefore particularly convenient for the identification of the causal effect that immigrants have on trade flows in and out of Italy. ${ }^{4}$

The fine administrative/territorial detail of the Italian data used in the analysis is supplementarily advantageous from an empirical standpoint. On the one hand, in line with some recent contributions on trade and immigration (Wagner et al. 2002; Dunlevy 2006; Bandyopadhyay et al. 2008; Briant et al. 2009; Peri and RequenaSilvente 2010; Herander and Saavedra 2005) the choice of a small spatial unit of analysis allows us to better control for unobserved heterogeneity (such as the matching of a the specific skill or task ability of a certain immigrant ethnic group and the production structure of the hosting geographical area) through fixed effects. ${ }^{5}$ On the other hand, the choice of the appropriate spatial unit of analysis is of primary relevance if there is evidence of a MAUP. As in the case of the 'ecological fallacy' (Jargowsky 2005) or the 'Simpson's paradox' (Samuels 1993), the bias associated with MAUP depends on the loss in variation due to data aggregation in arbitrary zonal units. In general, if the grouping process that guided the zonal aggregation is related to an omitted variable which is correlated with the variables of interest, the solution is to control for that omitted variable [see Briant et al. (2010) on this issue].

\footnotetext{
3 The Italian dataset guarantees the most extensive countries' coverage among those considered in the empirical literature, reducing the risk that the selection of specific countries may bias the estimates of the elasticity of trade to immigration.

${ }^{4}$ Colonial origins and linguistic proximity can both influence trade-and so they do in the traditional analyses of bilateral trade based on the gravity model [see Head et al. (2010), Helliwell (1999), Debaere et al. (2013) and De Benedictis and Taglioni (2011), Anderson (2011) and Head and Mayer (2014) for a review of the gravity model in international trade] — and immigration and, therefore, they can confound the relationship between immigrants and trade flows.

5 To the best of our knowledge, the Italian provinces are the smallest geographical entities used so far to investigate the link between immigration and trade.
} 
In our case, we can do better than that, tackling the MAUP at the origin through the use of both regional (NUTS-2) ${ }^{6}-20$ regions of an average size of 14,000 square $\mathrm{km}$ - and provincial (NUTS-3) Italian data-namely 107 Italian provinces of an average size of 2,800 square $\mathrm{km}$ - and comparing the results at the two levels of spatial analysis. ${ }^{7}$ The evidence goes in favor of the use of provincial data. This areal unit is also relatively more appropriate from a theoretical viewpoint. Indeed, the most popular explanations for the pro-trade effects of immigrants (see Sect. 2) are based on interactions and knowledge flows between natives and immigrants. These interactions are likely to depend on the distance between individuals, and are accordingly more precisely captured if the geographical units of analysis are small areas such as NUTS-3, rather than countries or NUTS-2 like regional units.

The choice of a very fine spatial unit of analysis comes with a problematic sideeffect: the very large number of (trading-pair) fixed effects necessary to control for (dyadic) unobserved heterogeneity. As it is explained in Online-Appendix C and Sect. 4, accounting for the role of zeros in the dependent variable, or in other terms including in the analysis the effect of immigrants on the extensive margin of trade, might imply serious computational problems. The use of nonlinear models such as the Pseudo Poisson Maximum Likelihood (PPML) estimator, proposed by Santos Silva and Tenreyro (2006) in order to reduce the estimation bias of log-linear models (Santos Silva and Tenreyro 2011), or the EK-Tobit model (Eaton and Kortum 2001), clashes with the use of a large set of fixed effects that hamper convergence. In what follows, we propose an empirical strategy to overcome the trade-off between the use of nonlinear estimators and the instrumental use of fixed effects to control for unobserved heterogeneity.

The data used in the analysis come mainly from two publicly available data sources collected by the Italian National Statistical Institute (ISTAT). Trade flow data refer to the value of imports and exports of 107 Italian provinces (NUTS-3) with 210 countries, over the period $2002-2009 .{ }^{8}$ The trade data are originally measured in euros, and report export and import flows between the Italian province

\footnotetext{
${ }^{6}$ For the unfamiliar reader, NUTS stands for Nomenclature of Territorial Units for Statistics and is a European Union geocode standard for referencing the subdivisions of countries for statistical purposes. There are three zonal levels, NUTS-1, NUTS-2 and NUTS-3, which for Italy correspond to the country, region (regione) and province (provincia) levels, which also correspond to the three main administrative units of the country.

7 To be more precise, the mean area of Italian provinces is 2,816 square km with a coefficient of variation of 0.17 , almost 57 times tinier than American states (162,176 square km, when Alaska and Washington DC are included), and more than 200 times smaller than Canadian provinces (606,293 square $\mathrm{km}$ when Nunavut, North-West and Yukon territories are excluded). These administrative units are also much smaller and more regular in size with respect to French metropolitan départements and Spanish provinces. The mean area of French départements is 5,666 square $\mathrm{km}$ with a coefficient of variation of 0.33 (when Corsica and overseas French regions are excluded), whereas the related figures for Spanish provinces are 10,118 square $\mathrm{km}$ with a coefficient of variation of 0.47 (excluding Ceuta and Melilla).

${ }^{8}$ More precisely, we consider 103 provinces until 2006 and 107 afterwards. The number of Italian provinces changed in recent times, as reported by ISTAT. In the mid 1990s the number of Italian provinces was 103. In 2001 the Sardinia autonomous region established 4 new provinces, that became operative during 2005. In 2004 the Italian Parliament established 3 new provinces that became operative in 2009. The total actual number of provinces is 110. Since our dataset does not include observations for the years after 2009, we do not consider these latter changes in the number of Italian provinces.
} 
Table 1 Immigrants by country of origin (top 20)

\begin{tabular}{|c|c|c|c|c|c|c|}
\hline $\begin{array}{l}\text { Ranking } \\
\text { in } 2009\end{array}$ & $\begin{array}{l}\text { Country of } \\
\text { origin }\end{array}$ & $\begin{array}{l}\text { ISO3 } \\
\text { country } \\
\text { code }\end{array}$ & $\begin{array}{l}\text { Number of } \\
\text { immigrants }\end{array}$ & $\begin{array}{l}\% \text { of total } \\
\text { immigrants } \\
\text { in } 2009\end{array}$ & $\begin{array}{l}\text { Annual growth } \\
\text { rate, 2002/2009 } \\
(\%)\end{array}$ & $\begin{array}{l}\text { Ranking } \\
\text { in } 2002\end{array}$ \\
\hline (1) & Romania & ROM & 887,763 & 20.96 & 40.45 & (3) \\
\hline (2) & Albania & ALB & 466,684 & 11.02 & 11.76 & (1) \\
\hline (3) & Morocco & MAR & 431,529 & 10.19 & 10.51 & (2) \\
\hline (4) & China & $\mathrm{CHN}$ & 188,352 & 4.45 & 15.51 & (4) \\
\hline (5) & Ukraine & UKR & 174,129 & 4.11 & 68.99 & (28) \\
\hline (6) & Philippines & PHL & 123,584 & 2.92 & 9.67 & (5) \\
\hline (7) & India & IND & 105,863 & 2.50 & 16.99 & (9) \\
\hline (8) & Poland & POL & 105,608 & 2.49 & 20.04 & (15) \\
\hline (9) & Moldova & MDA & 105,600 & 2.49 & 60.20 & (40) \\
\hline (10) & Tunisia & TUN & 103,678 & 2.45 & 8.33 & (6) \\
\hline (11) & Macedonia & MKD & 92,847 & 2.19 & 16.25 & (12) \\
\hline (12) & Peru & PER & 87,747 & 2.07 & 14.60 & (10) \\
\hline (13) & Ecuador & EQU & 85,940 & 2.03 & 32.67 & (25) \\
\hline (14) & Egypt & EGY & 82,064 & 1.94 & 13.82 & (13) \\
\hline (15) & Sri Lanka & LKA & 75,343 & 1.78 & 11.99 & (11) \\
\hline (16) & Bangladesh & BGD & 73,965 & 1.75 & 20.27 & (20) \\
\hline (17) & Senegal & SEN & 72,618 & 1.71 & 10.24 & (8) \\
\hline (18) & Pakistan & PAK & 64,859 & 1.53 & 16.72 & (18) \\
\hline (19) & Serbia & SRB & 57,877 & 1.37 & 1.19 & (7) \\
\hline \multirow[t]{3}{*}{ (20) } & Nigeria & NGA & 48,674 & 1.15 & 12.97 & (19) \\
\hline & Top 20 countries & & $3,434,724$ & 81.1 & 20.66 & \\
\hline & TOTAL & & $4,223,154$ & 100 & 14.9 & \\
\hline
\end{tabular}

Source ISTAT

of shipment, i.e., the province where the custom transaction was registered, and the foreign country of destination (for exports) and of origin (for imports). ${ }^{9}$ Information on the number of foreign born residents by Italian province or region and foreign country of origin is obtained from ISTAT as well, and covers the same period. Our explanatory variable of interest is the stock of legal immigrants by country of origin (home country) and province (or region) of destination in Italy, defining immigrants as residents born abroad with a foreign nationality. ${ }^{10}$

\footnotetext{
9 The information of Extra-EU transactions is based on the "Documento Amministrativo Unico" (DAU), for the intra-EU exchanges the custom system has been replaced, since 1993, by the Intrastat standard. The original values of trade flows, in euros, have been converted in US dollars using the nominal exchange rate from the World Development Indicators (WDIs on-line database) in order to make them consistent with GDP data used in the gravity equations. The conversion is not influencing the results, since in the multivariate regression in Sect. 4 we use country time-varying fixed effects.

${ }^{10}$ Like all previous papers on the topic, we only consider legal immigrants. Direct information on the stocks of immigrants with illegal status is not available. However, Bianchi et al. (2012) using data on years in which there were immigration amnesties in Italy show a very high correlation between the number of illegal immigrants and the stock of legal immigrants already present at the province level.
} 


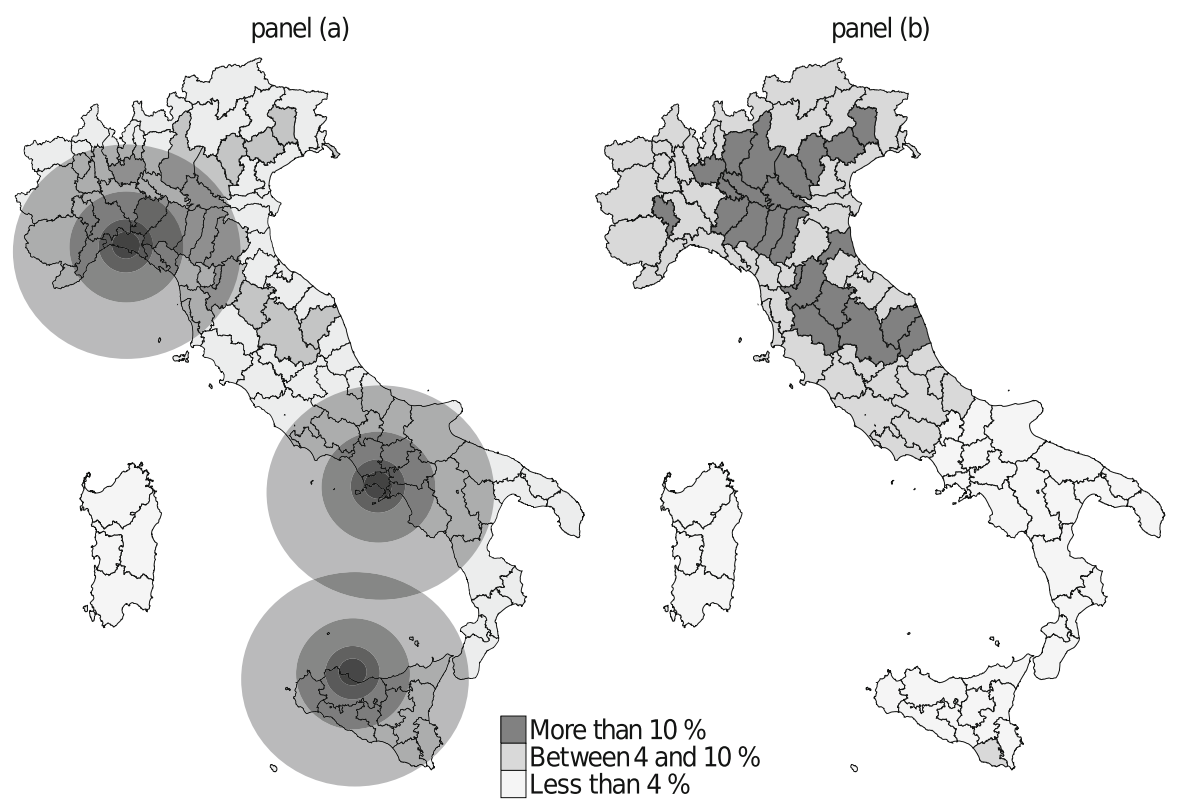

Fig. 2 Percentage of foreign-born population across Italian provinces. Year 2002 (a) and year 2009 (b). Note: The two cartograms plot the share of foreign-born population in the total population, with 'darker' provinces hosting a higher share of immigrants, in 2002 (a) and 2009 (b). The concentric circles around the cities of Genoa (in the North), Naples (in the South) and Palermo (in the Sicily island) in panel (a) describe the hypothetical boundaries for neighboring provinces 25, 50, 100 and $200 \mathrm{~km}$ apart. We limited three drawing to three exemplificative cases for graphical purposes

Of the 187 ethnic groups included in the dataset, Table 1 shows the top 20 countries of origin of immigrants in 2009. The top five countries by number of immigrants were Romania, Albania, Morocco, China and Ukraine, accounting for about $50 \%$ of the total foreign-born population. Comparing the rank of these top 20 countries of origin in 2002, and especially the average growth rate over the period, gives an idea of the change in the composition of immigrants by country of origin. In 2009, the majority of the foreign-born population came from Eastern Europe (Romania, Albania, Ukraine, Rep. of Moldova, Poland), the area which experienced also the highest growth rate of immigration over the period.

An interesting feature of the immigration pattern in Italy is the uneven distribution of immigrants across Italian provinces. Figure 2 shows a map of Italy where provinces are colored according to the share of foreign-born population in the total population, with 'darker' provinces hosting a higher share of immigrants. While in 2002 none of the 103 provinces registered a share higher than $10 \%$, in 2009 twenty three provinces exceeded the level of $10 \%$ of foreign born residents, mainly in the Center and the North of the country. The map of Italy also reveals some spatial clustering of immigrants: immigrant-abundant provinces are more likely to be close to each other. We address the potential consequences of this issue for our analysis in Sect. 5 where we account for spillover effects from immigrants 
Table 2 Migrants' location by province and country of origin

\begin{tabular}{lrrrrrrr}
\hline & Mean & SD & Min & $25 p$ & Median & $75 p$ & Max \\
\hline Year: 2002 & & & & & & & \\
$\quad$ Foreign nationalities per province & 111.92 & 23.39 & 49 & 97 & 112 & 128 & 175 \\
Provinces per foreign nationality & 82.07 & 24.37 & 1 & 68 & 95 & 102 & 103 \\
Year: 2009 & & & & & & & \\
$\quad$ Foreign nationalities per province & 124.91 & 20.46 & 58 & 113 & 126 & 139 & 179 \\
Provinces per foreign nationality & 90.23 & 22.35 & 1 & 83 & 100 & 106 & 107 \\
\hline
\end{tabular}

$25 p$ stands for 25 th percentile, while $75 p$ stands for 75 th percentile. The total number of Italian provinces is 103 (107 from 2006) while the total number of foreign nationalities is 187

of the same ethnic group in neighboring provinces, as visualized for the case of Genoa, Naples and Palermo as concentric circles in panel (a) of Fig. 2.

Although the distribution of foreign residents across provinces reveals a relative concentration in Northern Italy, the number of provinces with zero immigrants from a particular country of origin is rather small. This is an instance of the Italian 'superdiversity'. Table 2 reports the mean number of nationalities registered in each province at the beginning and at the end of the period under study: the value is around 111 in 2002, and about 125 in 2009. Provinces with less coverage of nationalities are in the South of Italy, as is intuitable from Fig. 2.

If we look at the distribution of immigrants from the perspective of each ethnic community, immigrants from the same country of origin located, on average, in 82 out of the 103 Italian provinces in 2002, and in 90 out of 107 Italian provinces in 2009. The distribution is far from being uniform: some immigrant communities are concentrated in a limited number of provinces (the minimum number of provinces for an immigrant community is just 1), others are spread all over Italy (the observed maximum always hits the theoretical one, i.e., the number of existing provinces). Focusing on the twenty most numerically relevant nationalities, we register huge differences in their geographical settlement. The most concentrated groups are from Egypt, Ecuador and the Philippines. In 2009, the distribution exhibits a coefficient of variation ${ }^{11}$ from 40 to $80 \%$ higher than the median value. On average, around $70 \%$ of these communities is located in the first five provinces of residence. The degree of concentration is relatively high compared to Albania, Morocco and Tunisia, the most evenly distributed nationalities. In this case the first five locations account for less than $25 \%$ of total residents. The most widely represented country of origin (Romania) records over 139,000 residents just in the province of Rome. The provinces of Rome and Milan, the administrative and economic centers of the nation respectively, play an attractive role that make them different from other provinces. We control for this peculiarity in the multivariate analysis reported in Sect. 4. The incidence of zeros in the full dataset is relatively high. On average we observe zero flows for $48 \%$ of imports and $29 \%$ of exports of province $i$ coming

\footnotetext{
${ }^{11}$ The coefficient of variation refers to the distribution of the province's share of the total number of foreign residents by nationality.
} 
from or directed toward the foreign country $j$, while for immigrants' stocks, the percentage of zeros is $39 \%$. The issue of zeros is also discussed in Sect. 4.

The definitions of the variables used in our analysis are reported in OnlineAppendix A.

\section{Empirical results}

The main steps of our empirical strategy are dictated by the need to control for possible reverse causality (from trade to immigration) and the omission of common variables affecting both trade and immigration in the same direction. We operate in sequence. In Sect. 4.1 we assume that, after controlling for a wide range of fixed effects, immigrant stocks are exogenous with respect to trade, and use ordinary least squares (OLS). In Sect. 5 we take into account the complexity of the trade data and allow for both geographic and inter-ethnic spillovers, still retaining the assumption of exogeneity. In Sect. 6 we deal with the remaining potential endogeneity of immigration, instrumenting the stock of immigrants with an imputed variable related to past ethnic diasporas in Italian provinces, and report 2SLS estimates. Finally, Sect. 7 sheds light on the possible heterogeneous effects of immigrants.

\subsection{Ordinary least squares and MAUP}

Our starting point is the following Anderson and Wincoop (2003) theoretically founded specification of the gravity equation: ${ }^{12}$

$$
\begin{aligned}
\ln \left(1+X_{i j t}\right)= & \delta_{r j}+\theta_{j t}+\phi_{r t}+\alpha \ln \left(Y_{i t-1} Y_{j t-1}\right)+\beta \ln \left(1+I_{M M_{i j t-1}}\right) \\
& +\gamma \ln \left(\text { distance }_{i j}\right)+\rho \text { contiguity }_{i j}+\epsilon_{i j t}
\end{aligned}
$$

where $i$ is the subscript for Italian provinces (NUTS-3), $r$ is the subscript for the region where province $i$ is located (NUTS-2), $j$ indicates the foreign country (i.e., the country of origin of immigrants), and $t$ stands for time. $\delta_{r j}$ are region-country (trading-pair) fixed effects, $\theta_{j t}$ are country-year fixed effects, and $\phi_{r t}$ region-year fixed effects. $X_{i j t}$ is trade (exports or imports) between province $i$ and country $j$ at time $t$. $Y_{i t-1}$ and $Y_{j t-1}$ are province and foreign countries GDPs at time $t-1$, respectively, and $I M M_{i j t-1}$ is the stock of immigrants from country $j$ located in province $i$, acting as a trade-enhancing force in contraposition with distance $e_{i j}$, which is the great-circle distance between province $i$ and country $j$. Contiguity $i j$ is a dummy for contiguity between the Italian province $i$ and the foreign country $j$, included to take into account possible nonlinearities in distance. Trade flows cover the 2003-2009 period and immigration stocks the 2002-2008 period. Covariates are

\footnotetext{
12 The Anderson and Wincoop (2003) specification of the gravity equation can be derived from microfoundations, and results from an expenditure function that takes into account the fundamental role of general equilibrium effects in trade: aka, the multilateral resistance index. See De Benedictis and Taglioni (2011), Anderson (2011) and Head and Mayer (2014) on the theoretical foundation of the gravity equation.
} 
predetermined and time-lagged. Finally, $\epsilon_{i j t}$ is an error term clustered at the province-country level.

In order to be consistent with the previous literature, we use a log-log version of the gravity model, and to retain observations with zeros in either trade flows or immigrant stocks, we follow Dunlevy (2006), Peri and Requena-Silvente (2010), Coughlin and Wall (2011), Artal-Tur et al. (2012) adding a constant equal to one to both bilateral trade flows and the stock of immigrants. Since trade is measured in dollar units (rather than thousands, millions or billions of dollars) this is likely to introduce only a small measurement error in the observations with zero trade (see Liu 2009). Previous contributions treated zero trade observations in different ways. Bandyopadhyay et al. (2008), for instance, restricted the analysis to the observations with positive trade. However, in general, doing this way one is likely to neglect the effect of immigrants on the extensive margin of trade (i.e., the existence of a trade link), which is likely to be a relevant dimension of the trade-creation effect of immigration.

It is worth noting that we are not including in the gravity equation provincecountry and province-year fixed effects because they would absorb almost all variation in both trade and immigration, leaving virtually nothing else to be explained (this is a crucial point in our analysis, and we give full account of it in Online-Appendix B). By contrast, we use larger geographical units (NUTS-2 administrative areas) to define region-country fixed effects $\left(\delta_{r j}\right)$, and region-year fixed effects $\left(\phi_{r t}\right)$. This enables us to control for unobserved heterogeneity at the regional level and still be able to exploit within-region variation across provinces (i.e., cross-sectional variation between provinces located in the same region) in both trade and immigration to identify the effect of interest. A similar approach was used by Wagner et al. (2002), which exploited cross-sectional variation between Canadian provinces to investigate the effect of immigration on trade. We bring their original idea a step further in the spatial dimension. Another reason to opt for a specification including region-country fixed effects is related to the IVs-based identification strategy we use in Sect. 6. As we report in that Section, when using a log-log specification and instruments based on a shift-and-share analysis, in which the lagged distribution of immigrants across provinces is used to build the instrument, including province-country fixed effects instead of region-country fixed effects, would make the 2SLS estimates be identified by nonlinearity only, and not by an exclusion restriction.

The specification of Eq. (1) is to the best of our knowledge one of the most comprehensive used in the literature in terms of the set of fixed effects included. Early papers did not include importer or exporter dummies (see, for instance, Head and Ries 1998; Girma and Yu 2002). Several subsequent contributions to the literature included importer and/or exporter fixed effects (Dunlevy 2006; Wagner et al. 2002; Santos Silva and Tenreyro 2006; Briant et al. 2009). Some recent papers using sub-national level data include trading-pair and year fixed effects (Bandyopadhyay et al. 2008) or trading-pair and country-year fixed effects (Peri and Requena-Silvente 2010; Coughlin and Wall 2011) but region-year fixed effects are generally omitted. In our specific case, trading-pair fixed effects are likely to 
account for factors that may spur trade between an Italian region and a specific country such as cultural proximity or historical ties (e.g., past Italian emigration from a given province toward a certain foreign country), country-year dummies are likely to capture time-variant foreign countries' economic, social and political events (e.g., the entry in the EU, military conflicts or economic crises) which are likely to affect both trade and migration flows toward Italian provinces, and regionyear dummies capture features such as the state of the local economy which may affect both trade and immigration flows from foreign countries. Hence, the focus on sub-national variation within the same country coupled with the inclusion of a wide range of fixed effects is likely to attenuate the potential endogeneity problems of immigration with respect to trade. For this reason, we use in this section the OLS estimator, clustering standard errors at the province-country level.

We also report the results from specifications that include fewer fixed effects, to stress the importance of controlling for unobserved heterogeneity. In these specifications we also include (for comparison with previous analyses at the European level) a dummy for EU or EFTA countries, whenever it is not absorbed by the fixed effects included (or not dropped due to collinearity). Panel (a) of Table 3 reports the results for exports. In column (1) we report the results of a specification only including time dummies (year fixed effects): the estimated elasticity of exports with respect to immigration is very high, at 0.506 , meaning that a $1 \%$ increase in the stock of immigrants settled in an Italian province raises exports from that province to the country of origin of immigrants by about $0.5 \%{ }^{13}$ Column (2) reports a specification which is very popular in the literature, which controls for separate region, country and year fixed effects. The coefficient on the stock of immigrants more than halves (0.206). Column (3) extends this specification allowing for time-variant country and region fixed effects, which has however little effect on the estimated elasticity. Columns (4) and (5) show the importance of controlling for trading-pair unobserved heterogeneity through trading-pair fixed effects. Including such fixed effects has a huge impact on the estimated elasticity, which becomes 0.058 in our preferred specification of Eq. (1) (column (5)), i.e., almost 10 times smaller than in column (1).

When we consider imports - in panel (b) of Table 3-we find a similar fall in the estimated elasticities by progressively adopting richer specifications in terms of fixed effects. The elasticity of imports with respect to immigrants is 0.796 in column (1). It falls to 0.362 when adding trading-pair fixed effects in column (4). Also in this case, comparison of column (2) with the following columns shows that, as for exports, most unobserved heterogeneity is captured by the trading-pair fixed effects, and the estimated elasticity turns out to be only marginally affected by the inclusion of other fixed effects. In the benchmark specification in column (5) the elasticity of imports with respect to immigrants is 0.344 . Also for imports, as for exports, the coefficient on immigration is always statistically significant at least at the $1 \%$ level.

\footnotetext{
13 All provinces of Sardinia are omitted from the analysis in 2006. This depends on the fact that, as we said above, four new provinces were created in Sardinia and we do not have lagged values for the independent variables for 2006.
} 


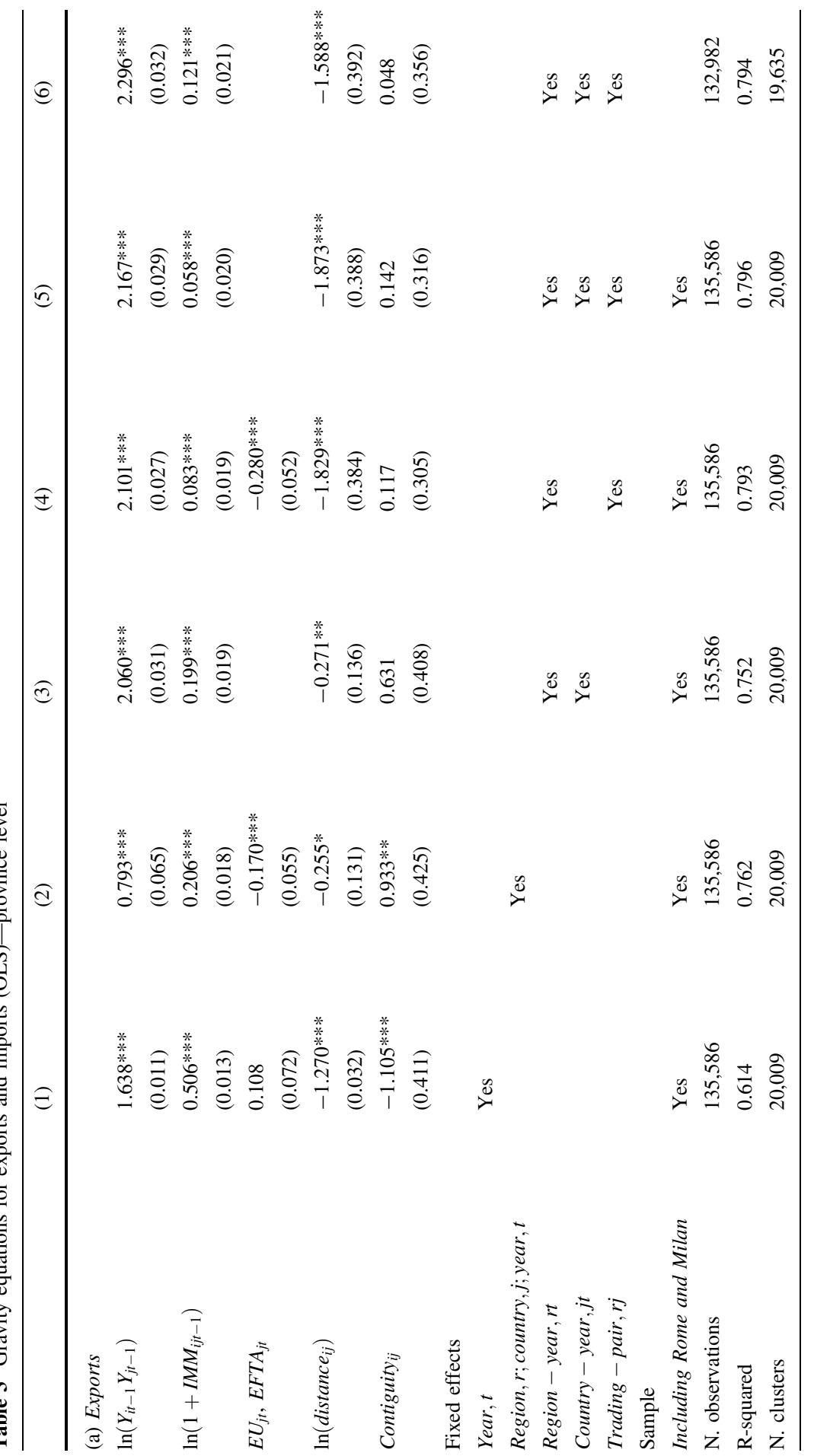




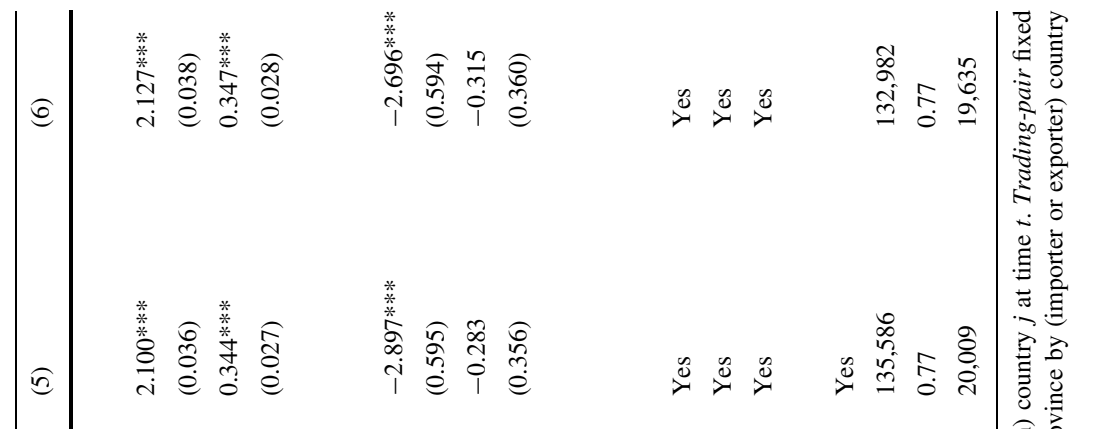

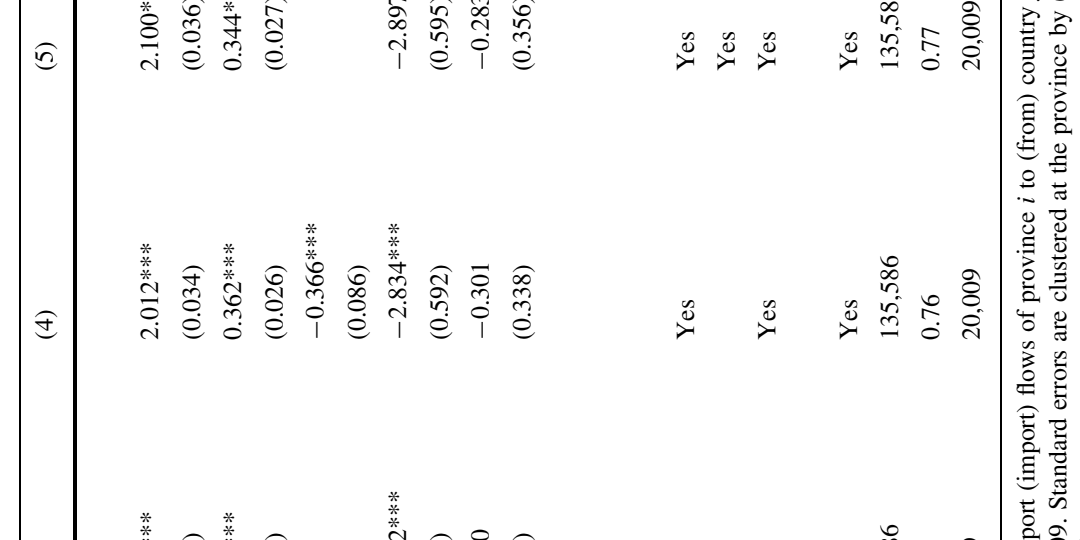

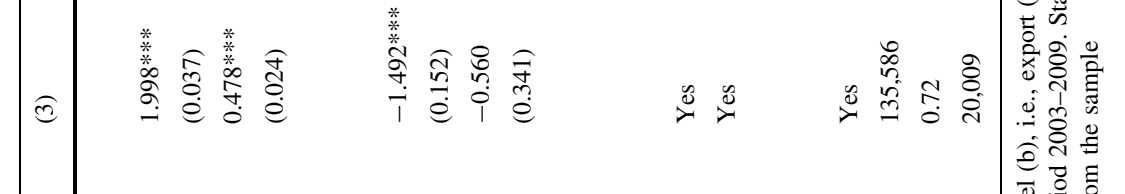

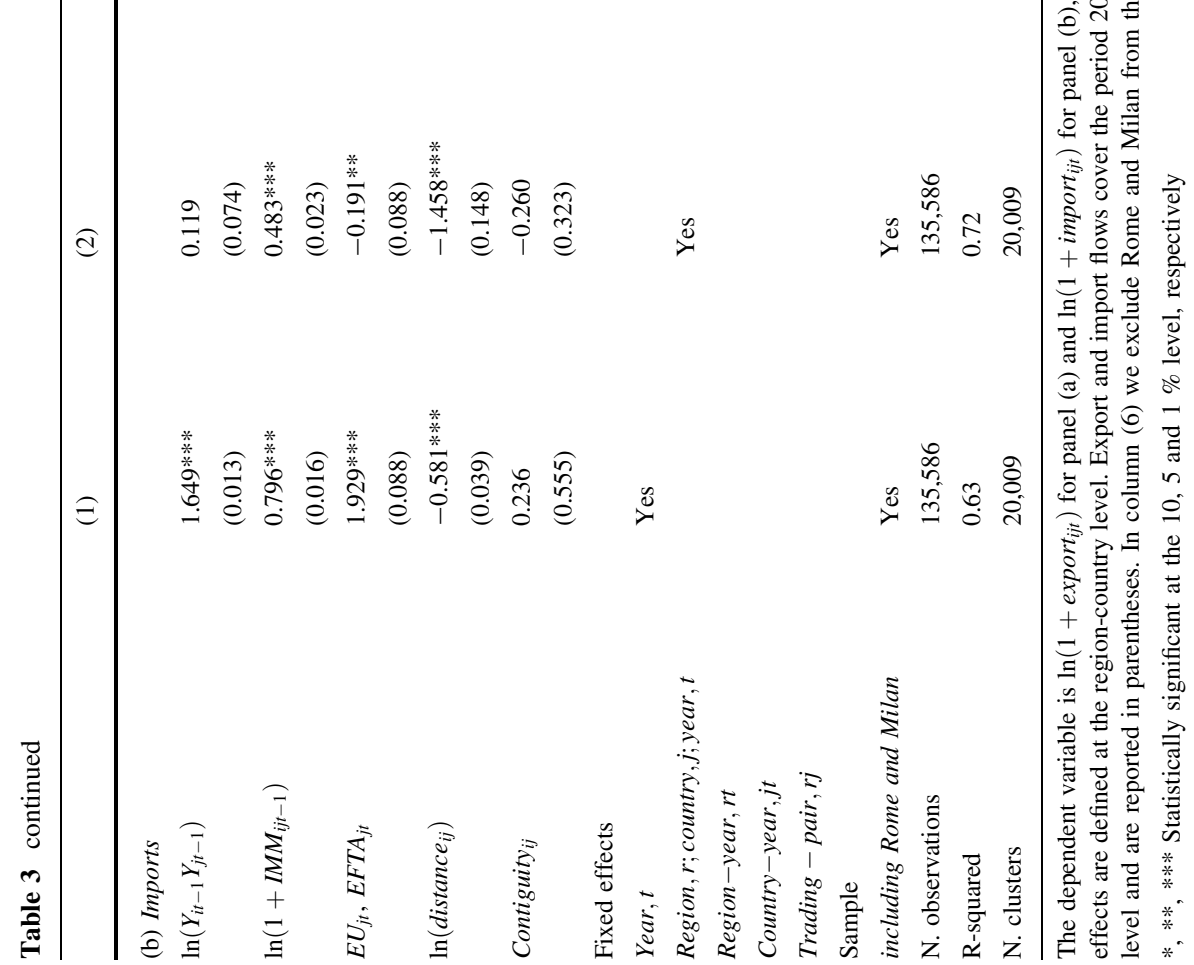


Thus, as predicted by economic theory and confirmed in most of the previous literature, our estimate of the elasticity of imports with respect to immigrant stocks is much larger than that of exports. This stems from the fact that while both the transplanted home bias effect and the business and social networks effects are at work for imports, only the second causal pathway affects exports.

The first step done, we deal now with possible concerns regarding the OLS estimates. To begin with, the log-log version of the gravity model has been recently subject to some criticism by Santos Silva and Tenreyro (2006). The debate on the most appropriate nonlinear estimator to be applied when zeros are a relevant proportion of trade flows is still very open. ${ }^{14}$ In the present case, the use of the PPML estimator proposed by Santos Silva and Tenreyro (2006) clashes with the inclusion of trading-pair fixed effects. The very high number of fixed effects prevents us from using any other nonlinear estimator or from applying the Heckit estimator as in Helpman et al. (2008) or the threshold Tobit model of Eaton and Tamura (1994) to account for zero-trade observations, since both require estimating a Probit model which suffers from an incidental parameters problem. ${ }^{15}$ In conclusion, controlling for unobserved heterogeneity through region-country fixed effects, which appears to be crucial according to Table 3, makes the log-log specification the sole feasible option among the many possible different alternatives. For the sake of brevity, a full account of our attempts to deal with zero-trade observations is reported in Online-Appendix C. More in general, the present case is indeed paradigmatic in terms of the trade-off between accounting for unobserved heterogeneity in trade data (through fixed effects) and using nonlinear models to estimate the gravity equation.

We checked nonetheless the sensitivity of our results to alternative transformations of the dependent variables (exports and imports) which allow us to retain the zero-trade observations in the estimation but still maintaining the linear specification. We tried (i) adding to exports and imports 0.1 (i.e., 10 cents of a dollar) instead of one dollar before taking natural logarithms; and (ii) using an inverse hyperbolic sine (IHS) transformation (Burbidge et al. 1988). ${ }^{16}$ Using the benchmark model of column (5), in the first case we obtain point estimates of 0.027 and 0.369 for exports and imports respectively, while in the second case (IHS) the estimates are 0.049 and 0.352. In both cases, the estimates were not statistically different from those reported in column $(5)$ of Table $3 .^{17}$

\footnotetext{
${ }^{14}$ See De Benedictis and Taglioni (2011) and Head and Mayer (2014) on this specific point of the gravity literature.

${ }^{15}$ In general, studies using a poisson specification or other nonlinear models adopt a much less richer set of fixed effects. Just to take two examples, Helpman et al. (2008) include separate importer, exporter and year fixed effects, while Eaton and Tamura (1994) include separate region, sub-continent and year fixed effects.

${ }^{16}$ The inverse hyperbolic sine (IHS) transformation consists of replacing $X_{i j t}$ with $\ln \left(X_{i j t}+\left(X_{i j t}^{2}+1\right)^{1 / 2}\right)$. In this case, as in the traditional logarithmic transformation, if the values of $X_{i j t}$ are not too small, the coefficients of the covariates can be interpreted as elasticities.

${ }^{17}$ Like for all the attempts enumerated in Online-Appendix C, all these estimates are available from the authors upon request.
} 
A second issue involves the peculiarity of Rome and Milan, the two largest cities in Italy. Their specificity is associated with their nature of trade hubs, size and density of economic activity, the peculiar characteristic of a capital city (for Rome) and the main Italian economic center (for Milan), and the associated historical presence of ethnic enclaves. Indeed, thanks to the presence of agglomeration economies, firms located in these two cities are likely to be the most productive and efficient, and export their goods irrespective of the presence of immigrants. In other words, they may act as outliers in the trade-immigration relationship. This is indeed confirmed in Online-Appendix D, in which we estimate a negative association between immigrants and trade for Rome and Milan. For this reason, in column (6) of Table 3 we have reported the estimates excluding Rome and Milan. Interestingly enough, while the elasticity of imports remains virtually unchanged (0.347), the elasticity of exports doubles in magnitude (0.121) and is in line with that estimated in the past literature. On the basis of this evidence, and the peculiarity of Rome and Milan, we put more emphasis on the estimates excluding these two provinces. Accordingly, in later Sections we only present the 2SLS estimates excluding these provinces from the estimation samples. As we said, the inclusion of these provinces generally tends to lower the magnitude and significance level of the elasticity of exports with respect to immigration, while it has no effect for imports. $^{18}$

A third concern is related to the existence of spatial correlation in the error term. This issue is further discussed in Sect. 5. Here, we simply estimate specification (6) with standard errors which are robust to the presence of very general forms of spatial dependence in the data (Driscoll and Kraay 1998). Since the routine used to compute the standard errors (Hoechle 2007) did not provide them at the first attempt, we partialled out all fixed effects from the dependent and the independent variables, and then estimated the models using the residuals. We did not observe any relevant change in the statistical significance of the coefficient of the stock of immigrants. ${ }^{19}$

A final concern regards the appropriate choice of the spatial unit in case there is evidence of a MAUP. As we explained above, a unique feature of our dataset is that it gives us the opportunity to deal with the MAUP in a very straight way, assessing the impact of the size of the areal units chosen on the magnitude and the significance of trade elasticities to immigration. We estimated a specification similar to Eq. (3) on regional data and the results are reported in Online-Appendix E. Curiously enough when working with the regional dimension, and controlling for trading-pair fixed effects, the relationship between trade and the stock of immigrants looses statistical significance and even turns negative. This analysis shows the potential advantages of working with very small geographical units when assessing the impact of immigration on trade. In summary, the comparison of the province-level

\footnotetext{
18 The complete set of estimates is available from the authors upon request. We also estimated the benchmark specification on the whole sample but including province fixed effects to account for the specificity of Rome and Milan, and obtained estimates very close to those in column (5). We then preferred to omit from the sample these two provinces given their clear nature of outliers in the tradeimmigration relationship (see Online-Appendix D).

19 Estimates are available upon request.
} 
with the region-level results suggests that the MAUP is an important issue in the analysis of the pro-trade effects of immigrants. This implies that the geographical aggregation of the areal units makes a difference when estimating the relation of interest, and accordingly that geographic distance between natives and immigrant networks is a key factor. Indeed, were these effects not affected by distance, we would not observe any difference in the coefficient estimates when assessing the link at the province or at the region level, i.e., using an aggregation of areal units positively correlated with distance. For this reason, in the next section we investigate more directly the potential importance of geographical spillovers for the trade-immigration nexus.

\section{Geographic and inter-ethnic spillovers of immigrants on trade}

Correlation across the errors of observations related to different provinces and different countries could be generated by omitted variables which are correlated with the included regressors. Take for instance Eq. (1) in which only immigrants from country $j$ in province $i$ are allowed to affect trade between province $i$ and country $j$. This is a restrictive specification. Indeed, one may posit that immigrants of the same nationality located in neighboring provinces also affect trade between $j$ and $i$. This may happen, for instance, because immigrants commute between provinces, so as they do not necessarily reside where they work. $^{20}$ This is a case of inter-province spillovers. These omitted stocks of immigrants may also be related with that in province $i$ generating an omitted variables bias.

The same could be said for immigrants of other nationalities located in province $i$. Equation (1) implies that networks from country $j$ only influence trade from and to $j$. But this is not necessarily the case. In fact, there might be inter-ethnic spillovers. ${ }^{21}$ As for imports, for instance, it is true that immigrants consume so-called ethnic goods, but these are not neatly differentiated across political borders. The imports from, say, Peru could be stimulated by the presence of large immigrant communities from other Latin American countries, for instance Ecuador, in the same province. Moreover, Peruvians' and Ecuadorians' location choices may be spatially correlated, generating an omitted variables bias if we omit the stock of Ecuadorians in the analysis of trade between Peru and province $i$. This is likely to happen especially for 'close' ethnic group, where closeness may be intended in terms of geographical distance of their countries of origin, cultural distance, consumption habits or in other dimensions. In all these cases correcting the standard errors is not enough and, to avoid an omitted variables bias, it is necessary to adopt a different specification which explicitly takes into account these potential spillovers. This is done in following subsections.

\footnotetext{
${ }^{20}$ Immigrant stocks in the gravity equation are defined by province of residence.

21 We thank an anonymous referee for having raised this issue.
} 


\subsection{Inter-province spillovers: the role of geographic proximity}

Most of the papers existing in the literature, and the specification of Eq. (1), do not allow for geographic spillovers from immigration on trade. However, taking into account potential spillovers is important. Province $i$ may, for instance, have a low stock of immigrants coming from a specific country, but may be surrounded by provinces in which immigrants from that country are located in large amount. Now, depending on the geographic scale of ethnic networks, this province may also benefit from proximity to immigrant-abundant provinces. Moreover, if there are interprovince spillovers, and the provinces' immigrant stocks are spatially correlated, then the coefficient on a province's own immigration may also pick up the effect of immigrants located in other provinces, generating an omitted variables bias.

This issue was investigated by Herander and Saavedra (2005) for the US. The authors compared the estimated effects of local immigrant populations on US states' exports to the effects of out-of-state populations of the same immigrant group and found the former effect to be greater than the latter. They interpreted this result as consistent with the importance of proximity to immigrant networks. A similar approach is adopted in a recent article by Artal-Tur et al. (2012) who investigated the same issue for Italy, Spain and Portugal using NUTS-3 level data. As a proxy of spillovers, they considered the immigrants outside the province, and the immigrants in adjacent and non-adjacent provinces in a log-log specification estimated with OLS and found that all these variables, unlike the province's own stock of immigrants, were not significantly associated with trade.

Here, we exploit the very fine spatial disaggregation of Italian trade and immigration data to shed light on the importance of geographic proximity for the trade-creating effect of immigrants. In our specification, spillovers are captured by the number of immigrants of a given ethnicity located outside the province within a distance $d$ of $25 \mathrm{~km}$, between 25 and $50 \mathrm{~km}$, between 50 and $100 \mathrm{~km}$, between 100 and $200 \mathrm{~km}$, and over $200 \mathrm{~km}$, as visualized in panel (a) of Fig. 2 by the concentric circles drawn, as an example, in the case of Genoa, Naples, and Palermo. ${ }^{22}$ The simultaneous inclusion of all these controls allows us to have a clearer idea of the existence of, and of the spatial decay of, the spillovers related to ethnic networks. Indeed, we expect the amount of contacts between individuals living in different provinces, and knowledge spillovers accordingly, to decline with distance. The specification becomes

$$
\begin{aligned}
\ln \left(1+X_{i j t}\right)= & \delta_{r j}+\theta_{j t}+\phi_{r t}+\alpha \ln \left(Y_{i t-1} Y_{j t-1}\right)+\beta \ln \left(1+I M M_{i j t-1}\right) \\
& +\sum_{d=1}^{5} \lambda^{d} \ln \left(1+I_{M} M_{i j t-1}^{d}\right)+\gamma \ln \left(\text { distance }_{i j}\right)+\rho \text { contiguity }_{i j}+\epsilon_{i j t}
\end{aligned}
$$

and $d$ it is an index which takes values from 1 to 5 , for immigrants of ethnicity $j$ living in a different province within a distance of 25, 25-50, 50-100, 100-200 km and more than $200 \mathrm{~km}$ from province $i$, respectively.

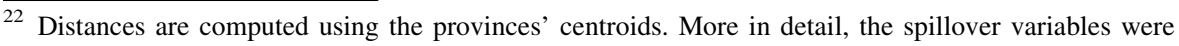
computed by aggregating the stocks of immigrants of all provinces falling within the radius $d$.
} 


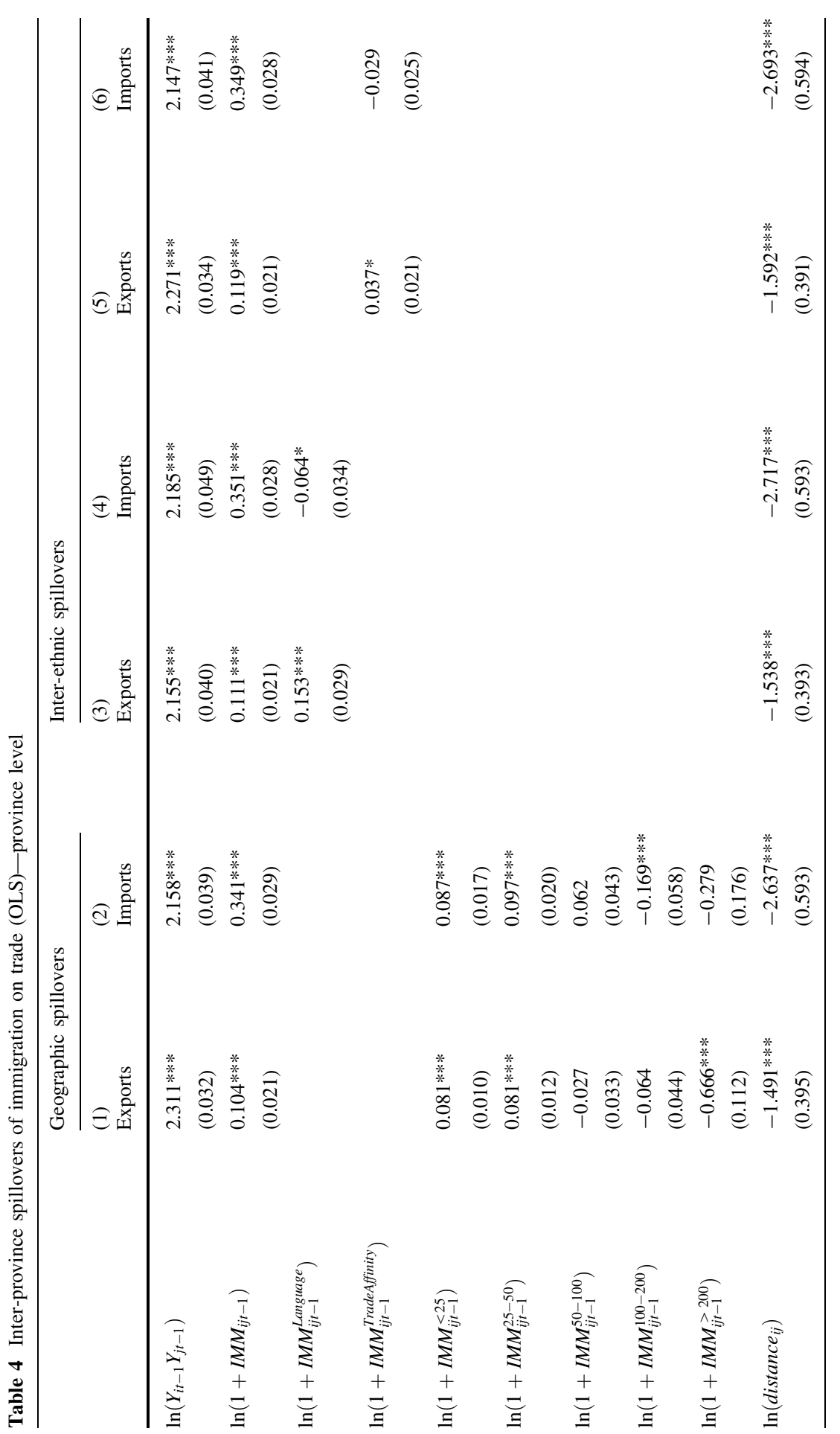




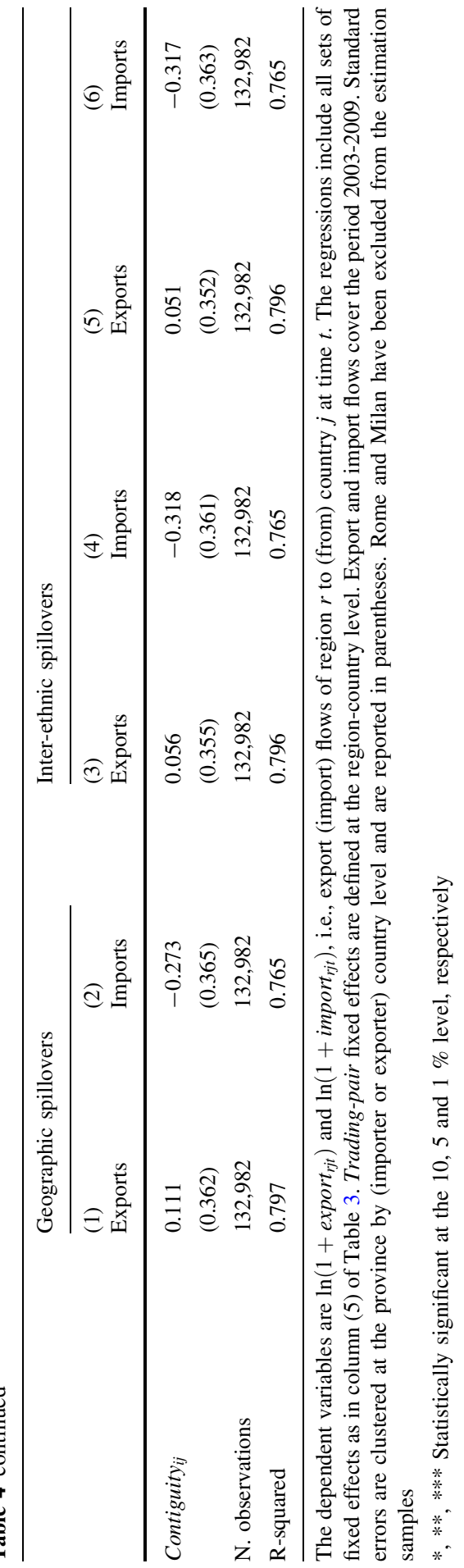


The results from the OLS estimation are reported in Table 4 and refer to the benchmark specification on the sample excluding Rome and Milan. Column (1) shows the results for exports. First, the coefficient for the province's own stock of immigrants is only slightly reduced by the inclusion of the spillover variables, and falls to 0.104 (instead of 0.121 , as reported in column (6) of Table 3). Immigrants of the ethnic group $j$, located within $50 \mathrm{~km}$ from province $i$ have a positive effect on export flows from province $i$ to the foreign country $j$. The effect of immigrants' stocks only slightly weakens for residents outside the province and within $50 \mathrm{~km}$, but turns significant and negative for ethnic networks which are located quite far away (more than $200 \mathrm{~km}$ ) from province $i$. We interpret this as evidence of a tradediversion effect. Indeed, the existence of provinces sufficiently distant from province $i$ which are abundant in immigrants from country $j$ puts them in a better position than province $i$ as far as trading with country $j$ is concerned. In simple terms, provinces seem to compete for the trade-enhancing factor embedded in immigrants. A similar pattern is observed for imports, as shown in column (2). Positive spillovers are also in this case observed within a distance of $50 \mathrm{~km}$, while they change sign for longer distances. However, on imports the effect of out of province immigrants is much lower than the one of those located in the province, which is marginally affected by augmenting the specification with spillovers $(0.341$ instead of 0.347 ). Taken together these results do not show a substantial omitted variables bias, and are broadly consistent with the findings of Herander and Saavedra (2005) and Artal-Tur et al. (2012) about the importance of geographic proximity for ethnic networks. However, we also find a trade-diversion effect (negative spillovers) when large stocks of immigrants are located 'too far away', and other provinces benefit from them.

\subsection{Inter-ethnic spillovers}

Although geographic spillovers have already been studied in the past, this paper is, to the best of our knowledge, the first one to provide some preliminary evidence on inter-ethnic spillovers. In order to shed light on inter-ethnic spillovers we first have to define 'close' ethnic groups, controlling for economic size and distance between countries. We take a simple approach and define proximity between ethnic groups in two ways. First, to build the spillover variable for nationality $j$ in province $i$ we aggregate all immigrants of other nationalities who speak the same language as nationality $j$ and located in the same province. ${ }^{23}$ Second, we use 'affinity in trade' between countries to build the spillover variables. In order to build this last variable, we start by estimating a gravity equation using an unbalanced panel of 211 countries over the period 1995-2002 (i.e., before our trade and immigrants stock are observed in our sample). Regarding the specification, we include time-varying fixed effects for both exporter and importer countries, to control for multilateral resistance terms; while to control for bilateral trade costs we include usual country-pair geographical variables such as distances, a dummy variable for borders, colonial ties, common

\footnotetext{
${ }^{23}$ The variable 'same language' is taken from Mayer and Zignago (2011). For any country pair it takes value 1 if a language is spoken by $9 \%$ (or more) of the population in both countries and zero otherwise.
} 
language, and a dummy equal to 1 if the two countries shares a Preferential Trade Agreement and zero otherwise. Trade data are taken from the BACII dataset Gaulier and Zignago (2010) while gravity controls are from Mayer and Zignago (2011). Then we used the average of the dyadic residuals for the whole period to define the degree of trade affinity between the countries' pairs. Intuitively, a positive residual implies that observed exports are higher than expected (given the specification of the gravity equation), which we interpret as a signal of affinity in trade. In what follows, the inter-ethnic spillovers are computed selecting the trade partner with highest residuals for each country, whose omission from the gravity equation should cause the largest omitted variables bias. As we can see from columns (3) and (4) in Table 4, augmenting the specification in Eq. (1) does not alter the direct effect of immigrants from country $j$ on trade between $i$ and $j$. Both for exports and imports the coefficient remains significant and of a comparable magnitude with respect to the original OLS specification (see column (6) in Table 3). The coefficient of the interethnic spillovers is not significant for import flows, bringing evidence of a strong average country specificity of tastes over ethnic-goods, while for exports the spillover effect is positive and significant irrespective of the spillover variable used. For exports, the size of the effect is much larger in the specification using language proximity than in that using trade affinity. This can be rationalized on the ground that most of the country pairs speaking the same language involve medium and low income countries, for which the effect of immigrants could be higher. ${ }^{24}$ In this sense, the spillover variable may act as a proxy of the stock of immigrants coming from less developed countries, and capture a substantial heterogeneity in the effect of immigrants by country of origin. We shed more light on this specific aspect in Sect. 7.

\section{Endogeneity and two-stage least squares}

The OLS results in Sect. 4.1 confirm the evidence in the raw data and suggest that immigrants may have a positive effect on both imports and exports, but larger for the former. However, a potential pitfall with the OLS estimates is that even after controlling for trading-pair fixed effects immigrant inflows may be endogenous with respect to export or import flows. The endogeneity problem could be determined, for instance, by trading-pair time-variant unobservables which simultaneously affect immigrant flows and trade. To the best of our knowledge there have been few attempts to address this issue in the literature. Combes et al. (2005) studied the role of domestic migrations in shaping trade between French regions. They sought to address the potential endogeneity of migrations by using the lagged stock of immigrants (15 years before). A similar instrument (lagged immigrant stock) is used by Briant et al. (2009) who focus on the trade-creating effect of foreign migrants in French departments. In both cases, the authors found

\footnotetext{
${ }^{24}$ Data inspection reveals that English, French, Arabic, Spanish and Portuguese are the most spoken languages in terms of country frequencies. The percentage of countries with yearly income less than 3,300 (12,000) US dollars (2002 value) are 52 (80), 85.7 (90.5), 60 (85), 60 (95) and 85.7 (85.7) for English, French, Arabic, Spanish and Portuguese languages, respectively.
} 
very similar elasticities when using OLS and 2 SLS. However, an important feature of their analysis is that, unlike we do, they used cross-sectional data and were not able to control for unobserved heterogeneity at the trading-pair level. ${ }^{25}$ An attempt to address the endogeneity of immigrants in panel data was made by Peri and Requena-Silvente (2010). The authors adopted a manifold strategy in building a potential instrument, based on supply-push factors and motivated by the presence of historical immigrant enclaves, as in Altonji and Card (1991). We apply the same approach in the present case. The presence of a community of immigrants from a given country in a certain Italian province is likely to decrease immigration costs and raise returns to migration for new immigrants of the same nationality that settle in that province. Indeed, co-nationals already present in a province may offer hospitality, financial support or help new migrants to find a job in the local labor market. For these reasons, we expect the stock of immigrants to be highly correlated with the inflow of new immigrants. Accordingly, we adopt the following procedure to build an instrumental variable. We compute the total stock of immigrants by country for Italy as a whole in each year, and we allocate it to each province according to the distribution of immigrants by nationality across provinces in 1995. This 'base' year for computing weights is chosen on the ground that before 1995 in Italy there were only 95 provinces, and considering early years the weight would be zero for eight provinces between 2002 and 2006, and for twelve provinces between 2006 and $2009 .{ }^{26}$ Since province-level data on the stock of immigrants by nationality are not provided by ISTAT for 1995, we use the distribution of immigrants' requests for residence permits ('permessi di soggiorno') provided by the Ministry of Interior. In this way, we compute an imputed stock of immigrants, which is used as an instrument for the observed stock.

More in detail, define $I M M_{i j t}$ the number of immigrants from country $j$ located in province $i$ at time $t$, and $I M M_{j t}$ the total stock of immigrants from country $j$ at time $t$ in Italy. Then the share of total migrants of nationality $j$ residing in province $i$ at time $t$ can be defined as

$$
w_{i j t}=\frac{I M M_{i j t}}{I M M_{j t}} .
$$

After considering the lagged distribution of immigrants by nationality across provinces $w_{i j 95}$ and having defined $I M M_{j 0}$ the total stock of immigrants from country $j$ at the first year of the time interval we consider (time zero, that is 2002), the imputed stock of immigrants becomes

\footnotetext{
${ }^{25}$ Indeed, Combes et al. (2005) only considered 1993, while Briant et al. (2009) took the average of trade flows over 3 years (1998, 1999 and 2000) for each département-country pairs. Hence, both these studies were unable to account for trading-pair unobserved heterogeneity.

26 As we said above, in 2006 four new provinces were created (in Sardinia), raising the total number of provinces from 103 to 107 . Hence, even fixing the base year at 1995, the instrument assumes value zero for these four provinces. We avoided imputing weights based on subjective assumptions, but checked the sensitivity to this issue by dropping observations for Sardinia after 2006, and did not obtain notable differences in the 2SLS estimates.
} 


$$
\widehat{I M M}_{i j t}=w_{i j 95} I M M_{j 0}+w_{i j 95} \sum_{q=0}^{t} F_{j q}=w_{i j 95}\left(I M M_{j 0}+\sum_{q=0}^{t} F_{j q}\right)=w_{i j 95} I M M_{j t}
$$

where $F_{j q}$ is the total net inflow of immigrants from country $j$ in Italy at time $q$. The instrument is then given by the product of two terms, the first ( $\left.w_{i j 95}\right)$ exhibits trading-pair variation, and the second $\left(I M M_{j t}\right)$ country by time variation. Thanks to the product of the two terms, the imputed stock of immigrants varies simultaneously at the province, country and time level. Imagine now that - as in the present casethe immigrant stock is measured in logarithms. After taking logs, Eq. (4) becomes

$$
\ln \left(\widehat{I M M}_{i j t}\right)=\ln \left(w_{i j 95}\right)+\ln \left(I M M_{j t}\right)
$$

that is linear in two terms, one varying at the trading-pair level and the other at the country-year level. This means that if one includes in the gravity equation provincecountry and country-year fixed effects, they completely absorb the instrument's variation. Adding one to the stock of migrants before taking logs makes it no longer possible to write the imputed stock of immigrants as a linear function of $\ln \left(w_{i j 95}\right)$ and $\ln \left(I M M_{j t}\right)$, that is

$$
\ln \left(1+\widehat{I M M}_{i j t}\right)=\ln \left(1+w_{i j 95} I M M_{j t}\right) \neq \ln \left(w_{i j 95}\right)+\ln \left(I M M_{j t}\right)
$$

and the variation in the log of the modified imputed stock of immigrants (i.e., the imputed stock after adding one) is now not completely absorbed by trading-pair and country-year fixed effects. However, in this case the 2SLS estimates' identification does stem only from the nonlinearity of $\ln \left(1+\widehat{I M M}_{i j t}\right)$ in these fixed effects, which may be too weak in many cases (see Table 8 in Online-Appendix B where only few residual variation remains after controlling for trading-pair fixed effects). ${ }^{27}$

As we said in Sect. 4.1, we do not only exploit this nonlinearity, but we also take advantage of the cross sectional variation between provinces within the same region, as we use trading-pair defined at the region-country level.

The main threat to identification comes from time-varying trading-pair unobserved factors during the period observed which simultaneously affect provinces' trade with a given country and the stock of immigrants from that country. In this respect, the main determinants of the imputed stock of immigrants in Eq. (4) are presumably exogenous, i.e., uncorrelated with such unobservables. Indeed, the net immigration flows by country to overall Italy in each year 2002$2008\left(F_{j q}\right)$ and the stock of immigrants by nationality in Italy in $2002\left(I M M_{j 0}\right)$, referring to the whole country, should not be affected by trading-pair shocks, especially when shocks are related to very small geographical units, such as Italian provinces. As for the remaining component, the distribution of residence permits by nationality across provinces in $1995\left(w_{i j 95}\right)$, conditional on trading-pair fixed

\footnotetext{
27 Peri and Requena-Silvente (2010) estimate, for instance, the impact of immigrants on trade of Spanish regions, and include in the gravity equation both region-country and country-year fixed effects. First, they add one to both trade and the immigrant stock to retain observations with zeros in their logarithmic specification, and, on top of that, in the 2SLS specification using the imputed stock of immigrants as the excluded instrument, they omit trading-pair dummies from the first stage.
} 


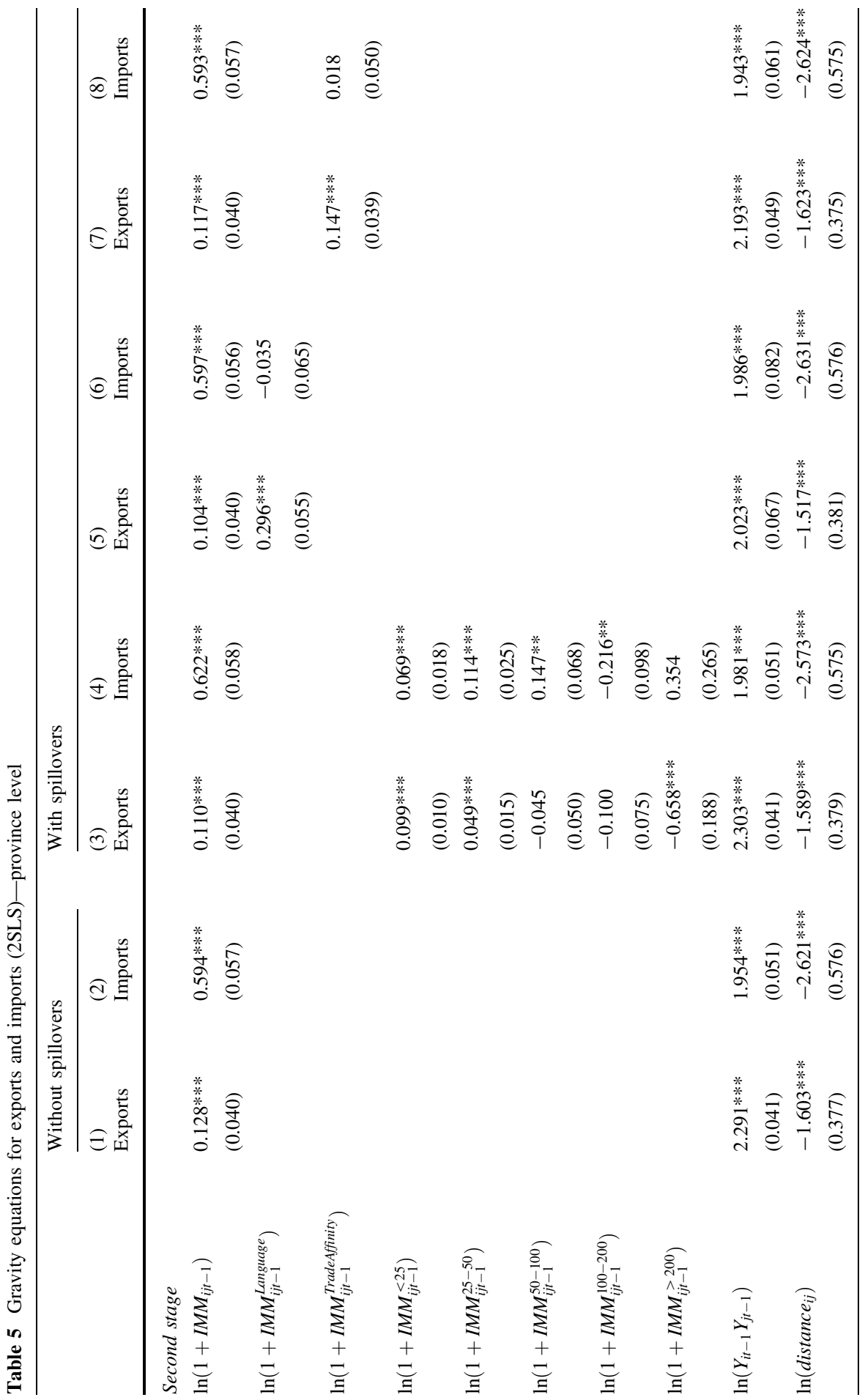




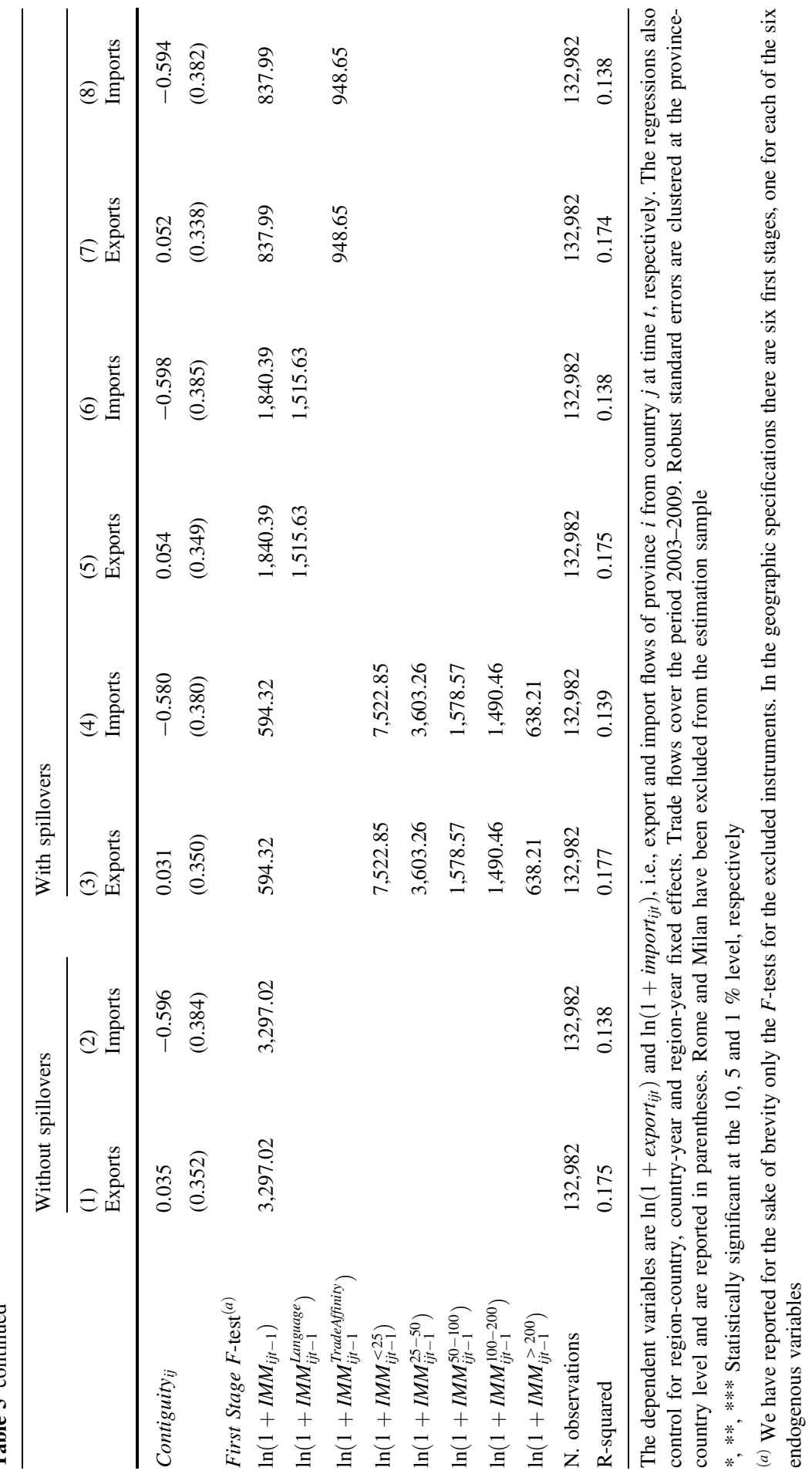


effects, region-year and country-year fixed effects, should not be theoretically correlated with any trading-pair time variant shock taking place during the estimation period (2003-2009), especially given that our geographic units of analysis (provinces) are relatively small. It may happen, for instance, that immigrants decided to locate in specific provinces in 1995 because they were predicting more local opportunities for trade growth with their home countries. However, controlling for trading-pair (region-country) fixed effects helps address this potential criticism, as the variation in the instrument which we are actually exploiting is only that between provinces within the same region and for the same country of origin of immigrants. For the instrument to fail it must be the case, for instance, that immigrants from a specific foreign country back in 1995 chose to locate in province $A_{1}$ rather than in province $A_{2}$ (both in region $A$ ) because $A_{1}$ offered the best opportunities for them to trade with their home country. However, this is very unlikely as provinces within the same region present the same (or very similar) institutional and, often, socio-economic characteristics, and therefore immigrants would have the same opportunity to trade with their home country irrespective of the specific choice of province of initial location. This is clearly an advantage of using very small geographical units of analysis, as this assumption would be much more difficult to maintain in country-level or even in region-level analyses. Moreover, the small size of provinces is important as it makes less likely that migration flows from a specific foreign country toward a single Italian province account for most immigration from that country toward Italy.

The results of the 2SLS estimation are reported in Table 5. Columns (1) and (2) show the estimates for the model without spillovers. In the first-stage, the instrument turns out to be very strong, with an F-test well above the threshold of 10 suggested by Staiger and Stock (1997) to detect a potential weak instrument problem. The export elasticity to immigrants is 0.13 , similar to that estimated with OLS (0.12). The estimated elasticity of imports is instead 0.59, larger than that obtained with OLS, and larger than for exports. Thus our estimates of the pro-trade effect of immigration are totally in line with the literature for exports, but larger for imports. $^{28}$

A potential problem with our identification strategy is related to the spatial structure of the data. In particular, we wonder whether the distribution of immigrants across Italian provinces in 1995 may be correlated with time-varying bilateral determinants of trade between 2003 and 2009. This could be the case if the distribution of immigrants of the same nationality but in other provinces in 1995 influenced the location choices of immigrants from country $j$ in province $i$ in the same year, which is in turn correlated with the current distribution, and there are inter-province spillovers in trade. A similar problem-also related to our previous analysis - could be generated if location choices of immigrants from other countries are correlated with those of country $j$, and there are inter-ethnic spillovers. In both

\footnotetext{
${ }^{28}$ In the IZA Discussion Paper's version of this paper we only reported the estimates for the sample including Rome and Milan. When including these cities the elasticity of exports falls to 0.004 and ceases to be statistically significant $(\mathrm{SE}=0.038$ ), while the elasticity of imports is only marginally affected $(0.548, \mathrm{SE}=0.053)$. This issue has been already discussed in Sect. 4.1 and Online-Appendix D.
} 


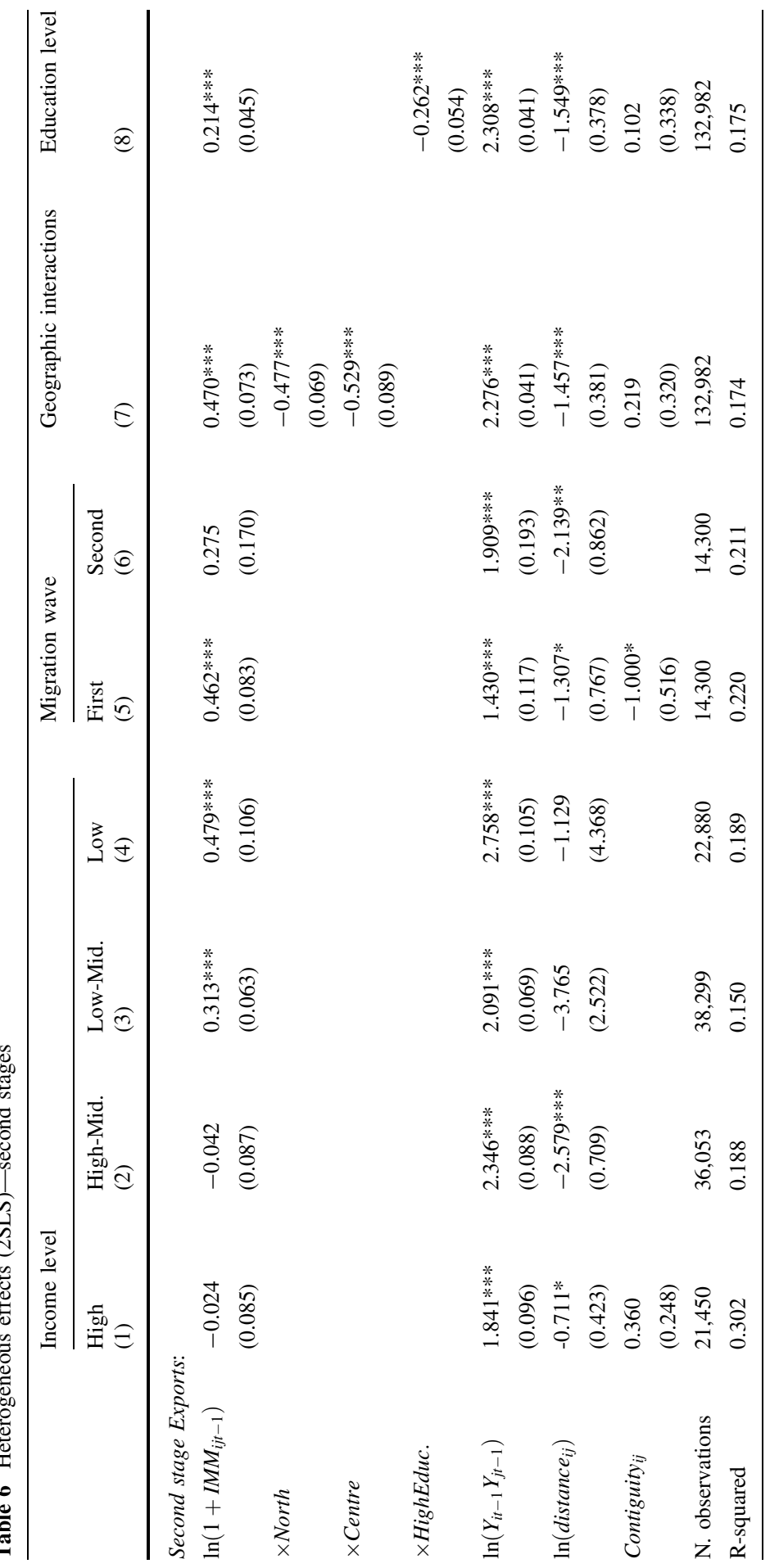




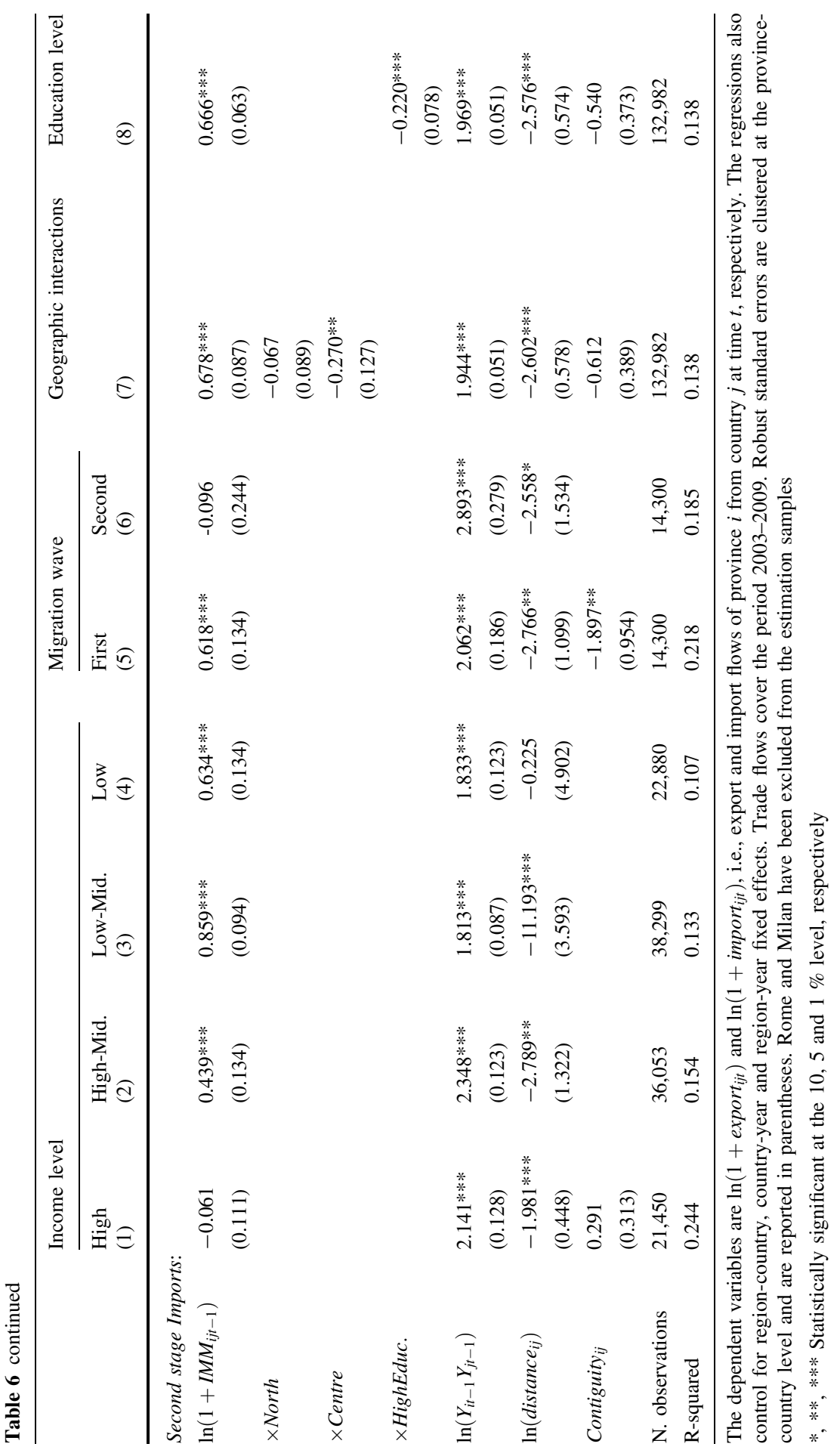


cases, estimating the specifications augmented with spillovers using 2SLS addresses these additional concerns.

In columns (3) and (4) of Table 5, we report the specifications augmented with the inter-province spillover variables (see Sect. 5), which have been instrumented using the same shift-and-share procedure used to instrument a province's own stock of immigrants. The 2SLS estimates show for exports a faster spatial decay of the effect of immigrants with distance compared with the OLS estimates in Table 4: the coefficients are 0.110 for the province's immigrant stock, 0.099 for immigrants within $25 \mathrm{~km}$ (in other provinces) and 0.049 for immigrants between 25 and $50 \mathrm{~km}$. The effect is negative for immigrants in farther provinces, but is significant only for the last category. For imports, the pattern of the coefficients is less clear cut. The coefficient on the province's stock of immigrants increases after including the spillover variables (from 0.594 to 0.622 ), which are significant and positive for the $25,25-50$ and 50-100 km categories, 0.069, 0.114 and 0.147, respectively, and negative and significant for the 100-200 km category, while the last category is not statistically different from zero. It is hard to explain the different pattern of geographical spillovers between imports and exports in the absence of additional data. A potential explanation is related to the two different channels captured by the coefficients (preference and business networks effects). In particular, the fact that the spillover for imports seems to have a lower spatial decay may be related to a variety of factors, such as the fact that immigrants may 'shop around', that is they may travel across provinces to buy ethnic goods when they are not available locally, especially when their supply is very spatially concentrated such in the case of ethnic quarters. Such short-run movements may contribute to increasing imports but are unlikely to transfer to natives relevant business-related knowledge, if the regions of destination of these travels are already rich in immigrants. Just to take an example, Chinese immigrants in the province of Pisa may for instance travel to Prato to buy Chinese goods. These internal migrations certainly benefit Chinese importers located in the Prato area, and spur their imports, while presumably they do not provide any additional knowledge about doing business in China to natives located in Prato, who already benefit from contacts with a large Chinese community.

The estimates with inter-ethnic spillovers based on linguistic proximity (i.e., speaking the same language) are shown in columns (5) and (6) of Table 5, and those based on 'trade affinity' in columns (7) and (8). Both sets of estimates confirm the early OLS results: inter-ethnic spillovers are statistically significant and positive only for exports. In any case, the coefficient on the province's own stock of immigrants is largely unaffected by the inclusion of the spillover variables, i.e., there is no evidence of an omitted variables bias. This is what is mostly relevant for the current paper, and for reasons of space a deeper understanding of the presence of inter-ethnic spillovers in trade is left for future work.

\section{Heterogenous effects}

When the effect of immigrants is heterogeneous, the IVs estimates reported in the previous section can be interpreted as Local Average Treatment Effects (LATE), 
i.e., as the effect on trade of the immigrants whose stocks are affected by the excluded instrument (the imputed stock of immigrants). In the presence of heterogenous effects, the LATE is an 'average' effect and may hide substantial differences across immigrants' countries of origin, or along other dimensions. In this section, we exploit the two-way geographical heterogeneity of our data to explore differential effects in the trade-creating effect of immigrants.

As we have already stressed, Italy provides two interesting features: (i) the 'super-diversity' of immigration; (ii) a remarkable socio-economic diversity across provinces, namely a strong North-South divide where Southern provinces lag behind in terms of economic development. As far as the first point is concerned, if immigrants are likely to reduce information costs, and contribute to enforcing contracts (Rauch 2001), this is likely to happen the lower the level of development of the countries where they come from. To test this hypothesis, we have classified immigrants' countries in four groups by level of Gross National Income per capita (in US dollars): low, middle-low, middle-high and high income. The classification is made by the World Bank, using an Atlas conversion factor to reduce the effect of exchange rate fluctuations on cross-country income comparisons and the list of countries in each category is included in Online-Appendix F. The results of the 2SLS estimation in the four samples are reported in columns (1)-(4) of Table 6. For the high-income countries no significant effect neither on exports nor on imports emerges. This is consistent with the hypothesis of these countries having well developed markets and institutions, which are likely to provide rich trade-related information and ensure contract enforcement without having to rely on the tradepromotion effort of their citizens abroad. Moreover, models of consumption are likely to be very similar across high-income countries, and we do not expect a strong transplanted home bias effect in consumption. Switching to the middle-high income category, we still do not observe any effect on exports, but a positive and significant effect on imports emerges. We tend to rationalize this effect as the consequence of partial differences in models of consumption between high-middle income countries and Italy, a high-income country. At lower levels of income, we find statistically significant effects on both exports and imports. For these countries, where market institutions are not well developed, immigrants are more likely to provide a valuable source of information and contract enforcement thanks to their persisting links with their home countries. For middle-low and low-income countries, a transplanted home bias is also likely to emerge, as the kind of goods immigrants were used to consume at home are less likely to be produced by Italian firms.

Another source of heterogeneity that we investigate is between 'new' (i.e., recently arrived) and 'old' communities of immigrants. We define two waves of immigration. The 'first wave' includes the first twenty countries of origin of immigrants, ordered according to the share in overall foreign born population in Italy at the beginning of the period (2002). The 'second wave' is defined similarly, but considering the first twenty countries of origin at the end of the period (2008), excluding those that were in the first wave's sample to avoid that the two groups overlap. The full list of countries is reported in Online-Appendix F. The results are reported in column (5) and (6) of Table 6. Interestingly, only first-wave immigrants 
seem to spur trade. A possible rationalization for this evidence is that knowledge flows from immigrants to natives need time to materialize, for instance due to immigrants' segregation, and accordingly recently arrived communities of immigrants are unable to spur trade. ${ }^{29}$ As for imports, even if there is a home bias in consumption, and new immigrants would prefer to consume their home goods, it takes time to organize import activities. For instance, imports from origin countries may require immigrants to create import-export firms (ethnic firms), or it may take time for 'native' firms to evaluate the existence of a potential market for 'ethnic goods', and its size. We leave further investigation of these hypotheses for future work.

Italy is characterized by a very strong North-South divide. Firms operating in the South are less productive (Aiello and Scoppa 2000) due to inefficiencies in the public sector, the presence of organized crime, credit constraints, loosely implemented institutional rules, which along with other factors make them also less likely to export (Castellani 2002). Firms located in the North of Italy are instead more productive and better integrated in the European market, as reflected by the average trade openness; over the sample period. ${ }^{30}$ Thus, in presence of market imperfections, immigrants may spur firms' exporting activities especially in the South. To investigate this hypothesis, the benchmark specifications of the export and import equations have been modified to include interaction terms between the stock of immigrants and macro-area dummies (North, Center, South and Islands). ${ }^{31}$ The results are reported in column (7) of Table 6 . In line with the theoretical predictions, a significant positive effect of immigrants on exports is estimated only for Southern Italy. The effect on imports turns out instead to be positive irrespective of the macro-region considered, suggesting again an important role for transplanted home bias in fostering import flows.

Early work suggests that immigrants of different age, type (family vs. individual), education and skills may have heterogeneous effects on trade. Head and Ries (1998) found for instance that independent immigrants, who presumably had stronger ties with their home country, had a larger impact on trade than family immigrants. Herander and Saavedra (2005) reported that older and skilled immigrants had a higher effect on trade. This could be rationalized with these immigrants having more information on their home country, either through life experience, education or skills. Unfortunately, ISTAT does not provide the socioeconomic characteristics of immigrants. However, we make an attempt to

\footnotetext{
29 This explanation is only apparently in contrast with our specification of the gravity equation in which the stock of immigrants at time $t-1$ affects trade at time $t$. First, using region by country fixed effects we are exploiting within-region variation across provinces, and not only yearly changes in the stocks of immigrants. Second, yearly changes in the stock of immigrants do not necessarily refer to first-time immigrants, but also to immigrants moving from other provinces. The probability that immigrants might have transferred from other provinces, and that they already have a good knowledge of Italy, is higher for first-wave immigrants.

30 The ratio between exports plus imports over GDP for the provinces located in the North of the country is about 0.51 , while for the Center is 0.39 , and for the South and Islands is 0.24 -far below the country's average 0.39 .

31 These interaction terms have been instrumented with interaction terms between macro-region dummies and the imputed stocks of immigrants.
} 
investigate heterogeneous effects by immigrants' education. We attributed immigrants to two educational categories (high educated vs. low educated) using data provided by Docquier et al. (2009), which records immigrant stocks by gender and educational attainment (primary, secondary and tertiary) in OECD countries in 1990 and 2000. Using data for Italy ${ }^{32}$ we rank the countries according to the percentage of tertiary educated immigrants and identify (using a dummy variable) as high educated nationalities those with a share above the median value. The regressions in column (8) show that are especially low-educated immigrants which spur exports. Indeed the effect is practically null for more educated (above median) immigrants. Results are similar for imports: the effect is larger for low educated immigrants, even though also highly educated immigrants have a positive effect on imports. These results mimic our early findings on heterogenous effects by GDP, as average education and GDP are highly correlated at the country level. The first-stage results of all models are reported in Online-Appendix $\mathrm{G}$ and show no evidence of a weak instruments' problem. ${ }^{33}$

\section{Concluding remarks}

This paper seeks to contribute to the literature on the causal effect of immigrants on international trade. The Italian case provides an ideal setting for shedding light on the trade-immigration link thanks to the large number of ethnic groups (187) present in the Italian territory, i.e., the Italian "super-diversity," the very fine geographical disaggregation of the migration and trade data (at the province level, NUTS-3), and the lack of colonial, language or cultural ties with immigrants' origin countries. The potential endogeneity of immigration is addressed using a shift-and-share approach based on the existence of immigrant enclaves. We have a number of interesting results. First, distance seems to be a key factor for the ethnic networks relevant to international trade. Indeed, although a province's own stock of immigrants generally has a larger effect than out-of-province immigrants, we find positive spillovers of immigrants within a distance of $50 \mathrm{~km}$ for both exports and imports. Interestingly enough, the spillovers change in sign when large communities of immigrants are too far away and other provinces are presumably benefiting from them (trade-diversion effect). We also provide preliminary evidence of inter-ethnic spillovers on trade: exports of province $i$ toward country $j$ are not only influenced by the stock of immigrants from country $j$ (located in $i$ ) but also by 'similar'

\footnotetext{
${ }^{32}$ In the case of Italy reference years are 1991 and 2001; in our case we use the earliest data.

${ }^{33}$ Since the Docquier et al. (2009) provides the skill structure of immigrants located in Italy for each country of origin, one could also have included three different variables for low, medium and highly educated immigrants in the gravity equation. However, this is not possible since the correlation coefficients between the three different stocks of immigrants are very high in our estimation sample: 0.981 between low and medium educated immigrants, 0.947 between low and highly educated immigrants and 0.985 between medium and highly educated immigrants. The high correlation between the three stocks depends on the fact that the actual stocks by educational level are not provided by ISTAT and must be imputed by applying the 2001 distribution by skill provided by Docquier et al. (2009) (which is time and province invariant in our estimation period) to the observed total stocks of immigrants by country of origin reported by ISTAT in each year.
} 
immigrants coming from other countries and located in the same province, where 'similarity' is defined either in terms of language proximity or affinity in trade. A similar effect is not found for imports. Second, our IVs estimates generally point to a larger effect of immigrants on imports than on exports. This is in line with the theoretical expectations, since imports are affected by both the transplanted home bias effect (i.e., the preference channel) and the business and social network effect of immigrants on trade, while exports only by the second effect. Using IVs, we estimate an elasticity of exports with respect of immigrants of 0.128 and of imports of 0.594 (specification without spillovers in Table 5, the estimates are similar when we account for spillovers). These figures imply that on average one more immigrant coming from a foreign country, settling in an Italian province would directly increase the yearly value of that province's exports toward that very country by 20,968 US dollars and of imports by 76,432 US dollars (effects computed at the sample mean of our estimation sample excluding Rome and Milan). Last but not least, we show that the average effect of immigrants on trade hides a substantial heterogeneity. Consistent with the idea of immigrants providing a valuable source of information and contract enforcement when market institutions are not well developed, we find the pro-trade effect of immigrants to be larger for immigrants coming from low-income countries, and for Southern Italy's provinces, in which firms are less productive and efficient. Moreover, trade creation appears to be larger for 'first-wave' immigrants, those who settled in Italy earlier. A possible rationalization of this last result is that the pro-trade effect of immigrants may originate not from information spillovers to natives but from immigrants exploiting their superior knowledge of the home country by organizing themselves importexport activities through ethnic firms. We leave further investigation of this hypothesis for future work.

Acknowledgments The research project started while Massimiliano Bratti and Luca De Benedictis were visiting UC Berkeley in 2010. Massimiliano Bratti wishes to thank IRLE and CLE and Luca De Benedictis the ARE Department for their hospitality. Luca De Benedictis and Gianluca Santoni received financial support by the Italian Ministry of Education, University and Research under the grant PRIN 2009 "The international trade network: empirical analyses and theoretical models" (www.netrade.org). We thank Rosalia Alessi, Antonella Ciccarese, Elena Mazzeo, and Alessia Proietti for their generous help with the data, and Massimo Tamberi for the references on super-diversity in migration. We also thank two anonymous reviewers, Sylvia Kuenne, and all the people who gave comments on previous versions of the paper, in particular Antonio Accetturo, Paolo Buonanno, Tommaso Frattini, Hubert Jayet, Giovanni Pica and participants in seminar and conference presentations at the Polytechnic Institute of Milan, the Solvay Brussels School of Economics \& Management, ERSA 2011 (Barcelona), ETSG 2011 (Copenhagen), ITSG 2011 (Milan), AIEL 2011 (Milan), SIE 2011 (Rome), 'Brucchi Luchino' 2011 (Rome), CIE 2012 (Granada) and EGI 2012 (Bari). A previous and partly different version of this paper circulated under the same title as IZA Discussion Papers 6628. The usual disclaimer applies.

\section{References}

Aiello, F., \& Scoppa, V. (2000). Uneven regional development in Italy: Explaining differences in productivitylevels. Giornale degli Economisti e Annali di Economia, 59(2), 270-298.

Altonji, J., \& Card, D. (1991). The effects of immigration on the labor market outcomes of less-skilled natives. In J. Abowd \& R. Freeman (Eds.), Immigration, Trade and the Labor Market. Chicago: University of Chicago Press. 
Anderson, J. E. (2011). The gravity model. Annual Review of Economics, 3, 133-160.

Anderson, J. E., \& van Wincoop, E. (2003). Gravity with gravitas: A solution to the border puzzle. American Economic Review, 93(1), 170-192.

Artal-Tur, A., Pallardó-López, V. J., \& Requena-Silvente, F. (2012). The trade-enhancing effect of immigration networks: New evidence on the role of geographic proximity. Economics Letters, 116(3), 554-557.

Atkin, D. (2013). Trade, tastes and nutrition in India. American Economic Review, 103(5), 1629-1663.

Bandyopadhyay, S., Coughlin, C. C., \& Wall, H. J. (2008). Ethnic networks and state exports. Review of International Economics, 16(1), 199-213.

Bianchi, M., Buonanno, P., \& Pinotti, P. (2012). Do immigrants cause crime? Journal of the European Economic Association, 10(6), 1318-1347.

Briant, A., Combes, P.-P., \& Lafourcade, M. (2009). Product complexity, quality of institutions and the pro-trade effect of immigrants. (CEPR Discussion Papers 7192), forthcoming in The World Economy.

Briant, A., Combes, P.-P., \& Lafourcade, M. (2010). Dots to boxes: Do the size and shape of spatial units jeopardize economic geography estimations? Journal of Urban Economics, 67(3), 287-302.

Bronnenberg, B. J., Dube, J.-P. H., \& Gentzkow, M. (2012). The evolution of brand preferences: Evidence from consumer migration. American Economic Review, 102(6), 2472-2508.

Burbidge, J. B., Magee, L., \& Robb, A. L. (1988). Alternative transformations to handle extreme values of the dependent variable. Journal of the American Statistical Association, 83(401), 123-127.

Castellani, D. (2002). Export behavior and productivity growth: Evidence from Italian manufacturing firms. Review of World Economics/Weltwirtschaftliches Archiv, 138(4), 605-628.

Combes, P.-P., Lafourcade, M., \& Mayer, T. (2005). The trade-creating effects of business and social networks: Evidence from France. Journal of International Economics, 66(1), 1-29.

Coughlin, C. C., \& Wall, H. J. (2011). Ethnic networks and trade: Intensive versus extensive margins. Economics Letters, 113(1), 73-75.

De Benedictis, L., \& Taglioni, D. (2011). The gravity model of international trade. In L. De Benedictis \& L. Salvatici (Eds.), The trade impact of European Union preferential policies: An analysis through gravity models, ch. 4 (pp. 55-89). Berlin, Heidelberg: Springer.

Debaere, P., Lee, H., \& Lee, J. (2013). Language, ethnicity and intra-firm trade. Journal of Development Economics, 103(C), 244-253.

Docquier, F., Lowell, B. L., \& Marfouk, A. (2009). A gendered assessment of highly skilled emigration. Population and Development Review, 35(2), 297-321.

Docquier, F., \& Rapoport, H. (2012). Globalization, brain drain, and development. Journal of Economic Literature, 50(3), 681-730.

Driscoll, J. C., \& Kraay, A. C. (1998). Consistent covariance matrix estimation with spatially dependent panel data. The Review of Economics and Statistics, 80(4), 549-560.

Dunlevy, J. A. (2006). The influence of corruption and language on the protrade effect of immigrants: Evidence from the American States. Review of Economics and Statistics, 88(1), 182-186.

Dunlevy, J. A., \& Hutchinson, W. K. (1999). The impact of immigration on American import trade in the late nineteenth and twentieth centuries. Journal of Economic History, 59(4), 1043-1062.

Eaton, J., \& Kortum, S. (2001). Trade in capital goods. European Economic Review, 45(7), 1195-1235.

Eaton, J., \& Tamura, A. (1994). Bilateralism and regionalism in Japanese and U.S. trade and direct foreign investment patterns. Journal of the Japanese and International Economies, 8(4), 478-510.

Epstein, G. S., \& Gang, I. N. (2004). Ethnic networks and international trade (IZA Discussion Paper 1232). Bonn: Institute for the Study of Labor.

Felbermayr, G., Jung, B., \& Toubal, F. (2010). Ethnic networks, information, and international trade: Revisiting the evidence. Annales d'Économie et de Statistique, 97(98), 41-70.

Gaulier, G., \& Zignago, S. (2010). BACI: International trade database at the product-level. The 1994-2007 version (CEPII Discussion Paper 2010-23). Paris: Centre d'Étude Prospectives et d'Informations Internationales.

Genc, M., Gheasi, M., Nijkamp, P., \& Poot, J. (2012). The impact of immigration on international trade: a meta-analysis. In P. Nijkamp, J. Poot, \& M. Sahin (Eds.), Migration impact assessmemt. New horizons in regional science, ch. 9 (pp. 301-337). Northhampton (MA): Edward Elgar Publishing Limited.

Girma, S., \& Yu, Z. (2002). The link between immigration and trade: Evidence from the United Kingdom. Review of World Economics (Weltwirtschaftliches Archiv), 138(1), 115-130. 
Gould, D. M. (1994). Immigrant links to the home country: Empirical implications for U.S. bilateral trade flows. The Review of Economics and Statistics, 76(2), 302-16.

Head, K., \& Mayer, T. (2014). Gravity equations: Workhorse, toolkit, and cookbook. In G. Gopinath, E. Helpman, \& K. Rogoff (Eds.), Handbook of international economics volume 4 (forthcoming). Amsterdam: Elsevier.

Head, K., Mayer, T., \& Ries, J. (2010). The erosion of colonial trade linkages after independence. Journal of International Economics, 81(1), 1-14.

Head, K., \& Ries, J. (1998). Immigration and trade creation: Econometric evidence from Canada. Canadian Journal of Economics, 31(1), 47-62.

Helliwell, J. F. (1999). Language and trade. In A. Breton (Ed.), Exploring the economics of language. Canada: Canadian Heritage.

Helpman, E., Melitz, M., \& Rubinstein, Y. (2008). Estimating trade flows: Trading partners and trading volumes. The Quarterly Journal of Economics, 123(2), 441-487.

Herander, M. G., \& Saavedra, L. A. (2005). Exports and the structure of immigrant-based networks: The role of geographic proximity. Review of Economics and Statistics, 87(2), 323-335.

Hiller, S. (2013). Does immigrant employment matter for export sales? Evidence from Denmark. Review of World Economics/Weltwirtschaftliches Archiv, 149(2), 369-394.

Hoechle, D. (2007). Robust standard errors for panel regressions with cross-sectional dependence. Stata Journal $V, 7(3), 281-312$.

ISTAT (2011). La popolazione straniera residente in Italia. Statistiche in breve-Istituto Nazionale di Statistica, Rome, Italy: Tech. rep., September 22.

Jargowsky, P. A. (2005). The ecological fallacy. In K. Kempf-Leonard (Ed.), The Encyclopedia of social measurement (Vol. 1, pp. 715-722). San Diego, CA: Academic Press.

Liu, X. (2009). GATT/WTO promotes trade strongly: Sample selection and model specification. Review of International Economics, 17(3), 428-446.

Mayer, T., \& Zignago, S. (2011). Notes on CEPII's distances measures: The GeoDist database. Working papers (CEPII Discussion Paper 2011-25). Paris: Centre d'Étude Prospectives et d'Informations Internationales.

Mazzolari, F., \& Neumark, D. (2012). The effects of immigration on product diversity. Journal of Population Economics, 25(3), 1107-1137.

Peri, G., \& Requena-Silvente, F. (2010). The trade creation effect of immigrants: Evidence from the remarkable case of Spain. Canadian Journal of Economics, 43(4), 1433-1459.

Rauch, J. E. (1999). Networks versus markets in international trade. Journal of International Economics, $48(1), 7-35$.

Rauch, J. E. (2001). Business and social networks in international trade. Journal of Economic Literature, 39(4), 1177-1203.

Rauch, J. E., \& Trindade, V. (2002). Ethnic Chinese networks in international trade. Review of Economics and Statistics, 84(1), 116-130.

Samuels, M. L. (1993). Simpson's paradox and related phenomena. Journal of the American Statistical Association, 88(421), 81-88.

Santos Silva, J. M. C., \& Tenreyro, S. (2006). The log of gravity. Review of Economics and Statistics, 88(4), 641-658.

Santos Silva, J. M. C., \& Tenreyro, S. (2011). Further simulation evidence on the performance of the poisson pseudo-maximum likelihood estimator. Economics Letters, 112(2), 220-222.

Staiger, D., \& Stock, J. (1997). Instrumental variables regression with weak instruments. Econometrica, 65(3), 557-586.

Vertovec, S. (2006). The emergence of super-diversity in Britain (Working papers 25). Oxford: Centre on Migration, Policy and Society, University of Oxford.

Vertovec, S. (2007). Super-diversity and its implications. Ethnic and Racial Studies, 30(6), 1024-1054.

Wagner, D., Head, K., \& Ries, J. (2002). Immigration and the trade of provinces. Scottish Journal of Political Economy, 49(5), 507-525.

White, R. (2007). Immigrant-trade links, transplanted home bias and network effects. Applied Economics, 39(7), 839-852.

White, R., \& Tedesse, B. (2007). Immigration policy, cultural pluralism and trade: Evidence from the White Australia policy. Pacific Economic Review, 142(2), 489-509.

WTO (2013). Fundamental economic factors affecting international trade. World Trade Report 2013 (pp. 112-219). Geneva, CH: WTO. 